\title{
Current Understanding of Papillary Thyroid Carcinoma
}

\author{
Rodrigo Arrangoiz ${ }^{*}$ (D), Jeronimo Garcialopez De Llano1, Maria Fernanda Mijares1, \\ Gonzalo Fernandez-Christlieb ${ }^{2}$, Vanitha Vasudevan' ${ }^{1}$, Amit Sastry', Adrian Legaspi ${ }^{1}$, \\ Jennifer Fernandez ${ }^{1}$, Frank de la Cruz ${ }^{1}$, Fernando Cordera ${ }^{3}$, Daniel Margain ${ }^{1}$ \\ ${ }^{1}$ Center for Advanced Surgical Oncology, Florida, USA \\ ${ }^{2}$ American British Cowdray Medical Center, Mexico City, Mexico \\ ${ }^{3}$ Sociedad Quirurgica S.C. at the American British Cowdray Medical Center, Mexico City \\ Email: ^rodrigo.arrangoiz@tenethealth.com, jerogldll@gmail.com, mfmo.md@gmail.com, g.fernandez@mail.harvard.edu, \\ vanitha.vasudevan@tenethealth.com,frankdlc@sanjuanbautista.edu, amit.sastry@tenethealth.com, \\ adrian.legaspi@tenethealth.com, fernando.cordera@gmail.com,dmargaint@gmail.com, jennifernandez.g24@gmail.com
}

How to cite this paper: Arrangoiz, R., De Llano, J.G., Mijares, M.F., Fernandez-Christlieb, G., Vasudevan, V., Sastry, A., Legaspi, A., Fernandez, J., de la Cruz, F., Cordera, F. and Margain, D. (2021) Current Understanding of Papillary Thyroid Carcinoma. International Journal of Otolaryngology and Head \& Neck Surgery, 10, 184-221. https://doi.org/10.4236/ijohns.2021.103019

Received: April 14, 2021

Accepted: May 22, 2021

Published: May 25, 2021

Copyright $\odot 2021$ by author(s) and Scientific Research Publishing Inc. This work is licensed under the Creative Commons Attribution International License (CC BY 4.0).

http://creativecommons.org/licenses/by/4.0/ (c) (i) Open Access

\begin{abstract}
The term thyroid neoplasm incorporates tumors that originate from follicular cells and those that arise from parafollicular cells (C cells). Differentiated thyroid cancer, which originates from follicular cells, includes papillary thyroid carcinoma (PTC), follicular thyroid carcinoma (FTC), oncocytic cell carcinoma (Hürthle), poorly differentiated carcinoma, and anaplastic thyroid carcinoma (ATC). PTC tends to have an indolent clinical course with low morbidity and mortality. However, this entity has a broad range of biological and clinical behavior that can result in disease recurrence and death, depending on patient and tumor characteristics and the initial treatment approach. PTC is the most common form of well-differentiated thyroid cancer (WDTC) and based on the most recent statistics, accounts for approximately 89.4\% of all thyroid malignancies. PTC appears as an irregular solid or cystic nodule in normal thyroid parenchyma. PTC has the propensity for lymphatic invasion, but it is less likely to have hematogenous spread. Around $11 \%$ of patients with PTC present with distant metastases outside the neck and mediastinum. This manuscript with review the current understanding of the epidemiology, pathology, molecular characteristics, prognostic factors, and dynamic risk stratification of PTC centered on an evidence-based and personalized approach.
\end{abstract}

\section{Keywords}

Thyroid Cancer, Papillary Thyroid Cancer, Papillary Thyroid Microcarcinoma, Thyroid Nodule, Thyroid Cancer Treatment, Molecular 
Studies for Thyroid Cancer

\section{Introduction}

Papillary thyroid cancer (PTC) tends to have an indolent clinical course with low morbidity and mortality. Nevertheless, this entity has a broad range of biological and clinical behavior that can result in disease recurrence and death, depending on patient and tumor characteristics and the initial management approach. PTC is the most common form of well-differentiated thyroid cancer (WDTC) and based on the most recent statistics, accounts for approximately $89.4 \%$ of all thyroid malignancies, and is the predominant histology observed in patients exposed to radiation [1] [2] [3] [4] [5]. The average age of diagnosis of PTC is between 30 and 40 years, women are affected more frequently than men at a 2:1 ratio [6] [7] [8]. PTC appears as an irregular solid or cystic nodule in normal thyroid parenchyma [9]. Notwithstanding its well-differentiated characteristics, PTC may be blatantly or minimally invasive. In fact, these tumors may spread easily to other organs [10]. PTC has the propensity for lymphatic invasion but it is less likely to have hematogenous spread [9]. Roughly $11 \%$ of patients with PTC present with distant metastases outside the neck and mediastinum [9]. In the past, regional lymph node metastases were thought to be aberrant (supernumerary) thyroids because they contained well-differentiated PTC, but occult regional lymph node metastases are now known to be a very common finding in patients with PTC [9] [11] [12] [13].

\section{Methods}

Literature published in the English language between 1970 and 2021 was searched via PubMed (MEDLINE), CrossRef, Google Scholar, Journal Seek, ResearchGate, National Science and Technology Library (NSTL), i-Scholar, and OvidSP (EMBASE). Original studies PTC, PTC epidemiology, PTC etiology, PTC pathology, thyroid cancer presentation, thyroid nodule work-up, thyroid cancer management were included.

\section{Epidemiology}

The American Cancer Society's most recent estimates for thyroid cancer incidence in the United States for 2021 are 44,280 new cases of thyroid cancer $(12,150$ in men and 32,130 in women) and approximately 2200 deaths from thyroid cancer (1050 men and 1150 women) [14]. The highest incidence of thyroid carcinomas in the world is found among female Chinese residents of Hawaii [14]. The rate of new cases of thyroid cancer was 15.7 per 100,000 men and women per year. The death rate was 0.5 per 100,000 men and women per year. These rates are age-adjusted and based on 2013 to 2017 cases and 2014 to 2018 deaths 
[1] [5] [15]. Roughly $1.3 \%$ of men and women will be diagnosed with thyroid cancer at some point during their lifetime, based on 2015 to 2017 data [1] [15]. In 2017 , there were an estimated 859,838 people living with thyroid cancer in the United States [1] [15]. Thyroid cancer develops in individuals of all ages but is most often seen in persons aged 45 to 54 , with a median age at diagnosis is 51 years [14]. In the younger population, PTC tends to occur more often than follicular carcinoma, with a peak in patients aged 30 to 50 years [14].

Approximately $67 \%$ of thyroid cancers are localized (confined to the primary site), $28 \%$ have spread to regional lymph nodes, and $4 \%$ had metastasized to distant sites [1]. The 5-year relative survival for localized thyroid cancer is $99.9 \%$, for patients with regional metastasis is $98.3 \%$ and with distant metastasis is $54.9 \%$ [1] [15].

\section{Pathophysiology and Etiology}

Chromosomal rearrangements were the first oncogenic events identified in PTC [16] [17], encompassing the rearranged during transfection (RET) proto-oncogene, which arises from a paracentric inversion of chromosome 10 [16] [17]. In nearly $20 \%$ of PTC the RET fusion proteins (the RET/PTC family) seem to have an oncogenic role, with the RET/PTC 1, RET/PTC 2, and RET/PTC 3 representing the vast majority of cases [17] [18]. In addition, the NTRK 1 and the MET proto-oncogene may be overexpressed and/or amplified [19] [20].

Evidence also suggests that some molecules that physiologically regulate the growth of the thyrocytes, such as interleukin-1 and interleukin-8, or other cytokines (e.g., insulin-like growth factor 1, transforming growth factor beta, epidermal growth factor) could play a role in the pathogenesis of this cancer [21].

Mutation in the BRAF gene resulting in the BRAF V600E protein is prominent in PTC. Mathur et al, in a single-institution study reported higher rates of BRAF V600E mutations in PTC from 1991 to 2005, proposing that this may be contributing to the rise in rates of thyroid cancer [22]. The BRAF V600E mutation is related with aggressive clinicopathological characteristics of PTC, including lymph node metastasis, extrathyroidal invasion, and loss of radioiodine avidity, which may lead to failure of radioiodine treatment and disease recurrence [23] [24].

The thyroid gland is very sensitive to the effects of ionizing radiation, both accidental and medical exposure to ionizing radiation has been linked to increased risk for thyroid cancer [25] [26]. Around 7\% of individuals exposed to the atomic bombs in Japan developed thyroid cancers [27]. The inhabitants, especially children, who lived in Ukraine during the Chernobyl nuclear accident have higher risk of developing PTC [28] [29] [30]. It has been documented that PTC in patients who have been exposed to radiation from the Chernobyl accident could be easily distinguished from sporadic PTC in patients with no history of radiation exposure, on the basis of gene expression profiles involving seven genes (i.e., SFRP1, MMP1, ESM1, KRTAP2-1, COL13A1, BAALC, PAGE1) [31]. 
From 1920 to 1960 , therapeutic irradiation was used to treat tumors and benign conditions, including acne; excessive facial hair; tuberculosis in the neck; fungus diseases of the scalp; sore throats; chronic coughs; and enlargement of the thymus, tonsils, and adenoids. Approximately 5\% to $10 \%$ of individuals who were treated with head and neck irradiation for such disorders developed thyroid cancer after a latency period of 30 to 50 years [32].

The greater exposure to diagnostic radiation, particularly computed tomography, is a potential culprit for the increased incidence of PTC [26]. Individuals who receive radiotherapy for certain types of head and neck cancer, especially during childhood, may have an increased risk of developing thyroid cancer [25]. Factors that heighten the risk for developing PTC after exposure to radiation include female gender, radiation for childhood cancer, and a family history of thyroid cancer [25].

There is some small evidence that polybrominated diphenyl ethers (PBDEs), that are flame retardants, that may be found in electrical appliances, plastics, televisions, computers, building supplies, foams, carpets, and upholstery, could possibly contribute to the development of thyroid cancer [33] [34]. PBDEs and their metabolites have a structural similarity to thyroxine and can accumulate in tissues [35]. These compounds have been shown to be endocrine disrupters, with thyroid and estrogen effects being the most common [33]. PBDEs have been shown to have increased oncogenic potential in other tissues which has made them a desirable candidate for additional research in thyroid cancer pathogenesis [36] [37].

Obesity has repeatedly been cited as a possible etiologic factor in the pathogenesis of thyroid cancer and has been postulated to be a possible origin of the increase incidence of this disease worldwide. Undeniably, being overweight and obesity have been associated with an increased risk of developing numerous malignancies, including thyroid, breast, colorectal, kidney, and endometrial cancers [14] [38] [39]. In the United States from 1995 to 2015, one out of every six PTC and two thirds of PTC greater than $4 \mathrm{~cm}$ in size have been linked to being overweight or obesity, based on an analysis of data from three large national US databases [40]. Kitahara et al. projected that the total relative risk for PTC was 1.26 for persons who are overweight (body mass index [BMI] 25 to $29 \mathrm{~kg} / \mathrm{m}^{2}$ ) and 1.30 for those who are obese $\left(B M I \geq 30 \mathrm{~kg} / \mathrm{m}^{2}\right)$, compared with persons with normal-weight BMI (18.5 to $24.9 \mathrm{~kg} / \mathrm{m}^{2}$ ) [40]. The risk in PTCs greater than 4 $\mathrm{cm}$ in size was nearly 3-fold higher (hazard ratio $[\mathrm{HR}]=2.93,95 \% \mathrm{CI} 1.25$ 6.87) with overweight individuals, and more than 5 -fold higher ( $\mathrm{HR}=5.42,95 \%$ CI 2.24 - 13.1) in obese individuals compared with normal-weight individuals. A study by Leitzmann et al. [41], found that obese adults had a nearly $40 \%$ higher risk for developing thyroid cancer when compared with normal-weight individuals. More research is needed to define the exact role of obesity in the development of thyroid cancer, particularly as the incidence of obesity continues to climb throughout the world [42] [43]. 
Most thyroid cancers are sporadic in nature; nonetheless, roughly $5 \%$ of nonmedullary thyroid cancers are hereditary [44]. These hereditary cases have been divided into two groups: those tumors associated with a familial cancer syndromes, such as Cowden's disease, familial adenomatous polyposis (FAP), and its variant Gardner's syndrome, Carney's complex type 1, and Werner's syndrome, and those with thyroid neoplasm's as the primary feature such as familial non-medullary thyroid cancer (FNMTC) [45]. Particularly FAP is associated with an elevated risk of developing a rare variant of PTC called cribriform morula variant of PTC (CMV-PTC) [46]. In a study by Uchino et al. [46], of 129 patients with FAP who underwent screening with cervical ultrasound identified 11 cases of PTC, eight of which were CMV-PTC. All the patients with CMV-PTC were women 35 years of age or younger [46].

FNMTC is defined by the presence of three or more first-degree relatives with well-differentiated thyroid cancer [47]. When only two family members are affected, only $38 \%$ will have FNMTC. When three or more family members are affected there is a $96 \%$ likelihood of having FNMTC [47]. The pattern of inheritance is autosomal dominant with incomplete penetrance [44]. Individuals with FNMTC will have a more aggressive biology compared to their sporadic counterparts [48].

Numerous articles have shown a connection between iodine deficiency and thyroid cancer [49]. Various other ailments have been linked as predisposing factors to PTC, including oral contraceptive use, benign thyroid nodules, late menarche, and late age at first birth [50] [51] [52] [53]. Smoking appears to be associated with a decreased risk of thyroid cancer [54].

\section{Pathology}

To make an accurate diagnosis of classic/conventional PTC the presence of nuclear features including intranuclear inclusions and nuclear grooves is a requisite [55]. The nuclei are larger than normal and often overlap and some may appear empty and are named "Orphan Annie nuclei." In PTC its nuclear characteristics differentiate it from other thyroid neoplasms, permitting it to be diagnosed on fine-needle aspiration (FNA) [56]. Furthermore, PTC is depicted by having branching papillae with a central fibrovascular stalk (Figure 1) [5] [57]. The branching papillae are covered by cells with eosinophilic cytoplasm [57] [58]. Cell polarity may be abnormal or completely lost in some tumors [51]. In some cases, squamous metaplasia may be present [57]. "Ghosts" of infarcted papillae, better known as Psammoma bodies, are essentially pathognomonic of PTC [59]. The Psammoma bodies are concentric, lamellated, calcified spheres composed in part of thyroglobulin are seen in roughly $50 \%$ of the cases [8] [57] [59] [60]. Some tumors may also contain multinucleated giant cells [5] [57]. Classical PTC, is typically unencapsulated with invasive and ill-defined margins [5] [61]. All the same, this common pathologic variant generally has an excellent prognosis [1] [5]. 


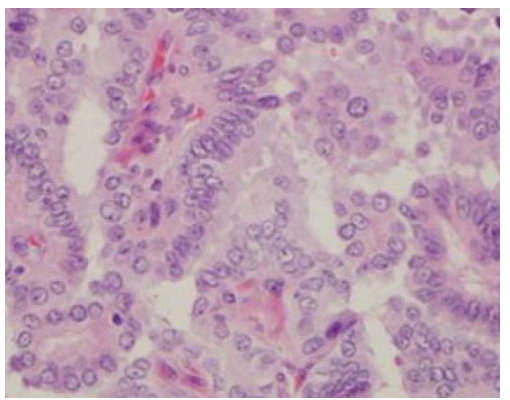

Figure 1. Conventional PTC.

The macroscopic appearance of PTC can be very variable. Most PTC tend to be distinctly well circumscribed, solid, firm, and white in color, but a significant percentage of tumors can be cystic [5] [57]. A relatively common presentation of PTC is cystic metastases to region lymph nodes and the presence of a solid primary tumor [62]. PTC may have depending on it biological aggressiveness can have an infiltrating growth pattern within the thyroid gland or may show a direct extrathyroid extension to adjacent tissues [8] [58]. Contrasting with a normal thyroid gland or benign thyroid neoplasms that protrude on sectioning, PTC remains flat [5] [60].

PTC has multiple pathologic variants (Table 1), which show unique patterns of clinical and biological behavior. Follicular variant of PTC (FVPTC) is similar to a follicular neoplasm when examined grossly. They are made up of follicles of various dimensions. The colloid is usually darker or hypereosinophilic compared to the colloid the adjacent normal thyroid parenchyma and may show scalloping "bubble gum" appearance (Figure 2) [7] [8]. Occasional multinucleated giant cells are present within the follicles. To establish the diagnosis of FVPTC the cytological features are indispensable (cells with enlarged nuclei with cytologic features of PTC) [7] [8], because this process can be rather problematic and contentious [63] [64]. The overall prognosis of FVPTC is similar to the conventional variant of PTC. An exemption to this is the diffuse or multinodular follicular variant, which has a more aggressive clinical course [8]. The prognosis of FVPTC also depends on whether they are entirely encapsulated or invasive [8] [65]. FVPTC can look similar to a follicular neoplasm except for the cytological features making them easily confused with follicular adenomas and follicular carcinomas, so the use of immunohistochemical and molecular markers can be very useful in confirming the diagnosis [57].

The tall cell variant (TCV) is made up of cells whose height is at least two to three times their width. In TCV PTC the cells have abundant eosinophilic cytoplasm and nuclear features similar to conventional PTC (Figure 3). Nuclear pseudo inclusions may be more prominent. TCV PTC tend to be larger than the classic PTCs, so necrosis, mitotic activity and extrathyroidal extensions are more prevalent. Most patients are older and present with large bulky tumors and are biologically more aggressive than the usual PTC, so they are more likely to demonstrate invasion, metastasis, and recurrence [7] [8] [57] [66] [67]. 
Table 1. Pathologic variants of PTC [1] [5] [57].

\begin{tabular}{cc}
\hline Pathologic Variant & Incidence \\
\hline Conventional/Classic & $65 \%$ to $85 \%$ \\
Follicular Variant & $15 \%$ to $20 \%$ \\
Tall Cell & $5 \%$ to $10 \%$ \\
Solid & $1 \%$ to $3 \%$ \\
Diffuse sclerosing & $1 \%$ to $2 \%$ \\
Papillary Micro-Carcinoma & \\
Oncocytic & \\
Columnar Cell & \\
Clear Cell & \\
Morular Cribriforme & \\
Marco-follicular & \\
PTC with Hobnail Characteristics & \\
PTC with Stroma Similar to Fascitis & \\
Combined PTC and Medullary Carcinoma & \\
PTC with dedifferentiation to Anaplastic Carcinoma & \\
\hline
\end{tabular}

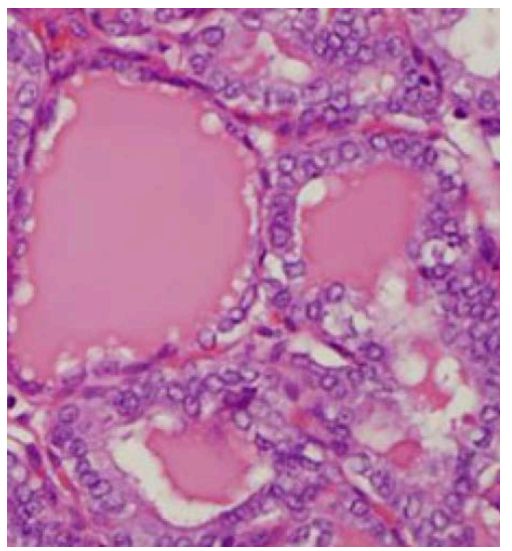

Figure 2. Follicular variant of PTC.

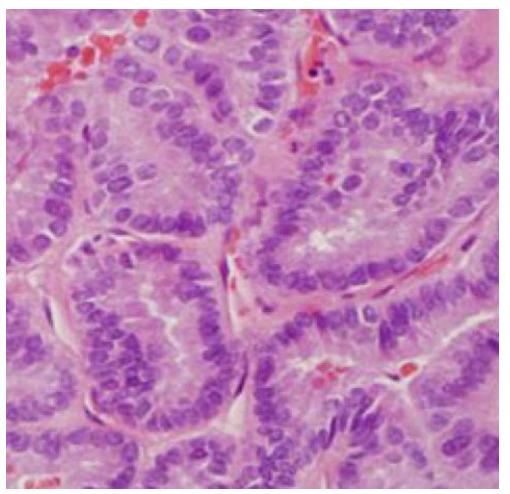

Figure 3. Tall cell variant of PTC. 
Solid cell variant (SCV) of PTC is made up of sheets of tumor cells, which have abundant cytoplasm and nuclear characteristic of PTC including cytoplasmic invagination into nuclei which are cytologic features of conventional PTC. (Figure 4) [68]. In roughly one third of cases vascular invasion and extrathyroidal extension are present [8] [57]. SCV of PTC is typically seen in children with a history of radiation exposure [57].

Oncocytic variant of PTC (OV) has a distinctive brown color on macroscopic inspection comparable to Hurthle cell neoplasms. OV PTC can have a follicular or papillary architecture (Figure 5) [69]. This oncocytic tumor has abundant lymphocytic stromal infiltrate, hence the name "Warthin-like" and is often seen with Hashimoto's thyroiditis [8] [57] [70]. The diagnosis is typically based on the nuclear features of PTC [57].

Clear cell variant PTC (CCV) is made up of chiefly by clear cells that have a papillary architecture and cytologic characteristics of PTC (Figure 6). Some CCV PTC may have oncocytic and clear cell features [8] [57]. Immunostaining for TTF-1 and thyroglobulin may be required to differentiate these tumors from a metastatic clear cell carcinoma [57].

Columnar cell variant of PTC is a rare subtype of PTC that consists of pseudo stratified columnar cells. A few cells may have supranuclear and subnuclear cytoplasmic vacuoles. Columnar cell variant of PTC may bear a resemblance to endometrial or colonic adenocarcinomas (Figure 7) [57] [71]. In columnar cell

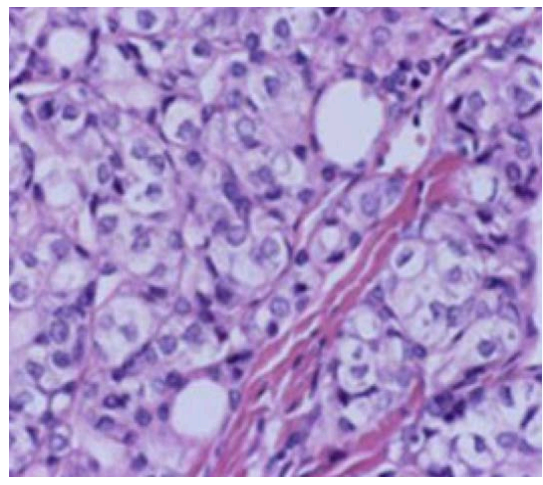

Figure 4. Solid cell variant (SCV) of PTC.

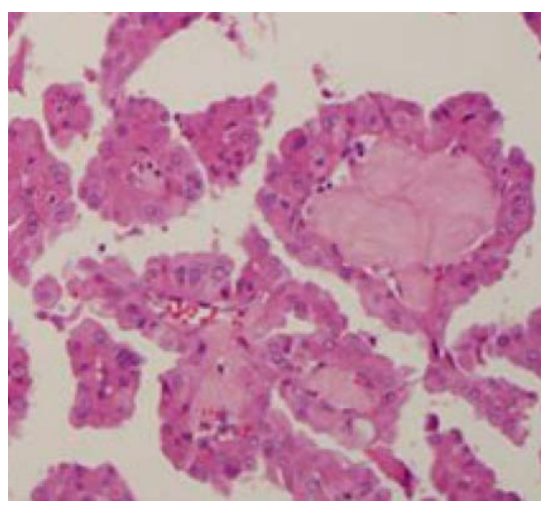

Figure 5. Oncocytic variant of PTC (OV). 


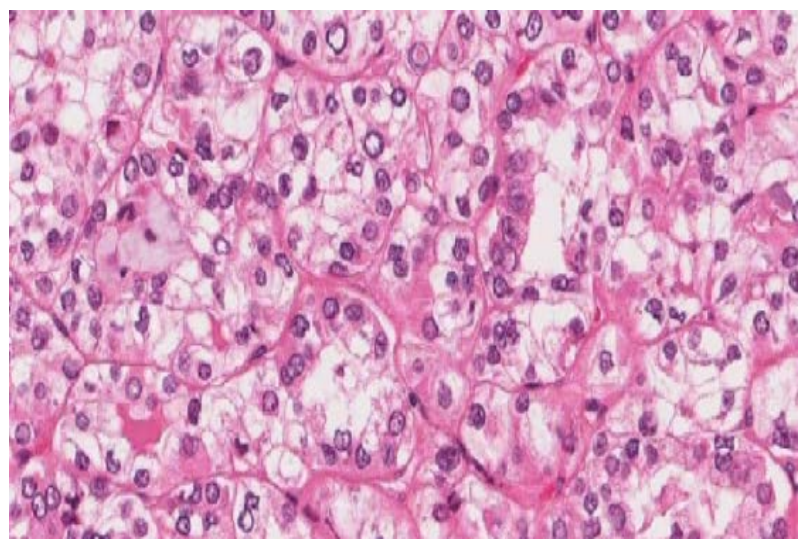

Figure 6. Clear cell variant PTC (CCV).

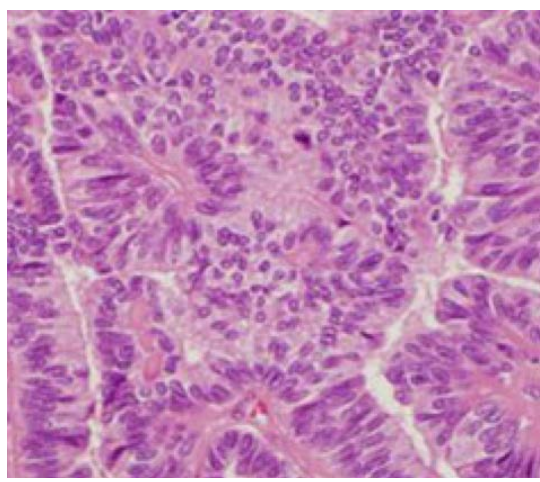

Figure 7. Columnar cell variant of PTC.

variant of PTC, the nuclear characteristics of classic PTC are not appropriately exemplified, so if the patient exhibits metastatic lesions, they may be mistaken for metastatic adenocarcinoma from lung, colon or endometrial cancers. Then again, the cells of columnar cell variant of PTC are typically positive for TTF-1 and thyroglobulin is inconsistently positive [7] [8] [57]. While various researchers consider columnar cell variant of PTC to be more aggressive than the conventional PTC, this conclusion is a bit more contentious. As with other subtypes of PTC, columnar cell variant of PTC that are entirely encapsulated are less likely to metastasize [57].

Diffuse sclerosing variant (DSV) represents approximately 5\% of all PTCs and is diagnosed more commonly in the pediatric age group and in patients between 15 and 30 years of age exposed to radiation [72] [73] [74]. DSV is a highly and diffusely infiltrative tumor, it is usually a bilateral tumor with $70 \%$ of the cases associated lymph node metastases [75]. Pathologically DSV PTC can be confused with chronic thyroiditis. Papillary structures in dilated lymphovascular spaces are a common finding. The DSV PTC show extensive squamous metaplasia, sclerosis, abundant psammoma bodies, stromal fibrosis, prominent lymphocytic infiltration, and rich lymphatic invasion [72]. The incidence of distant metastases are very variably depending on the series cited but appear to be higher than that of classic PTC [76] (Figure 8). 
Cribriform-morular variant (CMV) of PTC is most commonly associated with familial adenomatous polyposis (FAP) and its variant Gardner syndrome. CMV of PTC has a prominent cribriform pattern with solid and spindle cell areas as well as squamous morules (Figure 9). Focal papillary architecture is frequently identified. The nuclei show clearing and grooves focally. This variant usually is bilateral with multifocal lesions. The distribution of the CMV PTC is different between patients with and without FAP [77] [78] [79]. In patients without FAP, CMV-PTC often appears as solitary nodule with no site predilection [79]. Approximately $16 \%$ of the CMV PTC without FAP were bilateral. In patients with FAP, more than half develop bilateral cancers [77] [78] [79]. The prevalence of multifocal lesions is more usually noted in cases with FAP. In the literature, 118 cases had the data of FAP status as well as presence of multifocal lesions documented. In patients with FAP, $72 \%$ had multifocal cancers, whereas in patients without FAP, 24\% had multifocal cancers ( $\mathrm{P}=0.0001)$ [77] [78] [79]. Overall, multiple tumors were noted in 51\% of the CMV-PTCs. There is some debate in the literature as to whether this is a variant of PTC or a distinct lesion [8]. CMV of PTC is positive for thyroglobulin focally and shows positive nuclear staining for beta catenin.

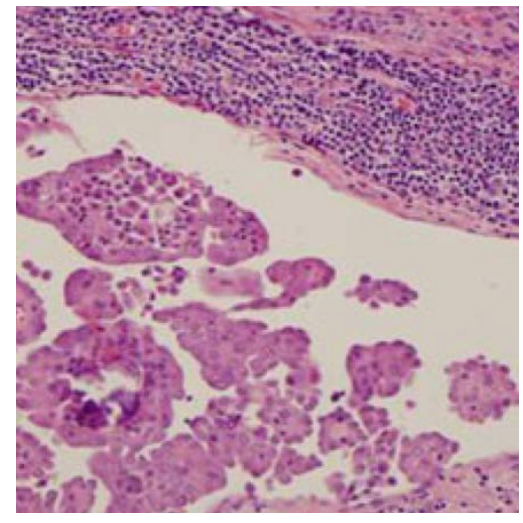

Figure 8. Diffuse sclerosing variant of PTC showing abundant psammoma bodies and squamous metaplasia.

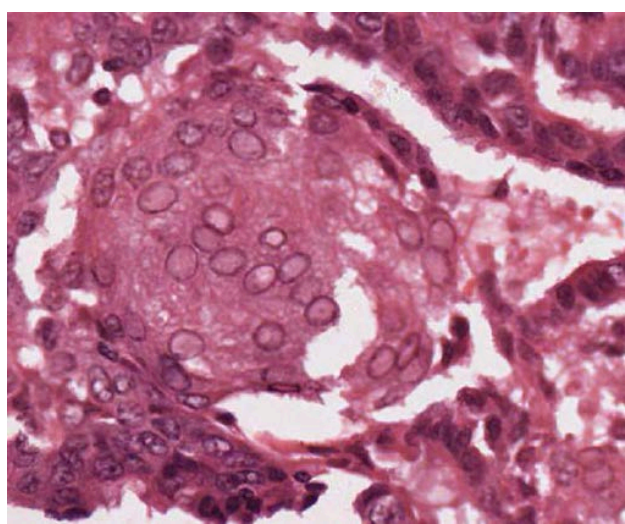

Figure 9. Cribriform-morular variant of PTC microscopic appearance: showing the morular areas composed of tumor cells with indistinct border and clear nuclei. 
Macrofollicular variant (MFV) of PTC is extremely uncommon, it is one of the rarest histological variants of PTC. MFV of PTC is a well-differentiated carcinoma made up largely of macrofollicles (greater than $50 \%$ of a cross sectional area) and can be easily confused with a hyperplastic or colloid nodules in low power magnification with the cytological features of PTC seen at higher magnification. The cells lining the follicles have nuclear features characterized by enlarged ground glass clear nuclei and nuclear grooves (Figure 10) [80]. MFV of PTC is typified clinically by its non-aggressive biological behavior, with a low incidence of metastases. When metastatic disease to regional lymph nodes is present it usually retains the macrofollicular pattern [72].

PTC with prominent hobnail features is a recently described rare variant [81] [82]. To determine the diagnosis of PTC with prominent hobnail features at least $30 \%$ of cells in the tumor are needed to display a hobnail-micro papillary pattern, though minor hobnail-micro papillary features are of consequence and should be noted in a pathology report (Table 2) [81] [82]. FNA cytology of these tumors will show micropapillary structures, loss of polarity, discohesiveness, and hobnail cells with teardrop appearance and soap bubble-like pseudo-nuclear inclusions (Figure 11). Tall cell and diffuse sclerosing patterns may be present in a small percentage of these tumors [81] [82]. The most commonly associated mutations reported in patients with PTC with prominent hobnail features is a BRAF V600E mutation which is associated with extra thyroidal extension, lymph node metastasis, distant metastasis, recurrences, and mortality [81] [83] [84].

PTC can sometimes manifest with extensive stromal proliferation, reminiscent of fibroblastic/myofibroblastic proliferative lesions in the soft tissue [85]. This rare variant of PTC has been described as PTC with nodular fasciitis-like stroma (PTC NFS) or PTC with fibromatosis-like stroma (PTC FMS) [57] [85] [86]. Histologically, it is made up of stromal components rich in spindle cells, occupying $60 \%$ to $80 \%$ of the tumor, and small foci of epithelial components showing typical features of classic PTC (Figure 12). Macroscopic and immunohistochemical findings have shown that the spindle cell stroma has the characteristics

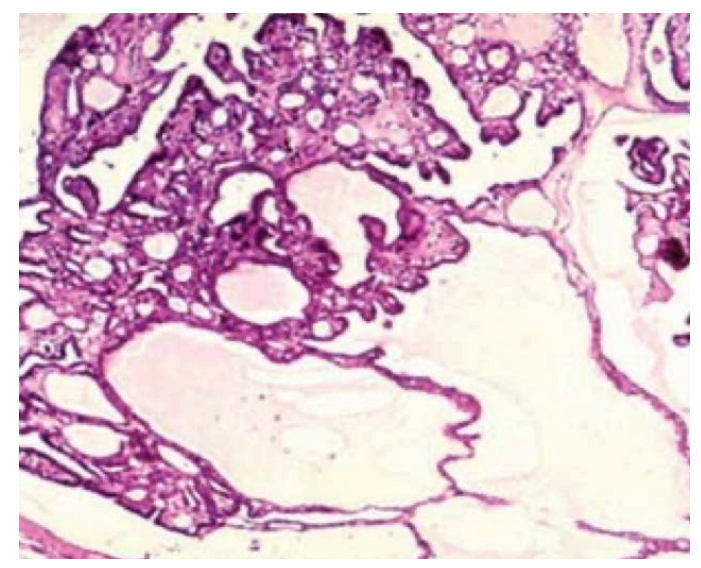

Figure 10. Macrofollicular variant (MF) of PTC with macrofollicles and can be easily confused with a hyperplastic or colloid nodules from low power magnification. 
Table 2. PTC with prominent hobnail features was originally described using the following criteria for the histological diagnosis [81] [82].

\section{Criteria for the Histological Diagnosis}

- Non-solid variant of PTC

- $\leq 10 \%$ of the tumor showed tall/columnar cell or diffuse sclerosing features

- Loss of polarity/cohesiveness with hobnail features in $\geq 30 \%$ of tumor cells

- PTC features are present showing papillary and micro papillary structures in the histopathologic smears

- High magnification shows nuclear pleomorphism, occasionally pseudo-inclusions with multiple soap bubble-like inclusions, and possibly mitotic figures

- Along with the PTC cellular findings HPTC can show papillary and micro papillary structures closely linked by cells containing eosinophilic cytoplasm and apically located nuclei with prominent nucleoli

- The cells that line these complex papillary structures have increased nuclear to cytoplasmic ratios and apically placed nuclei that produce a surface bulge (hobnail)

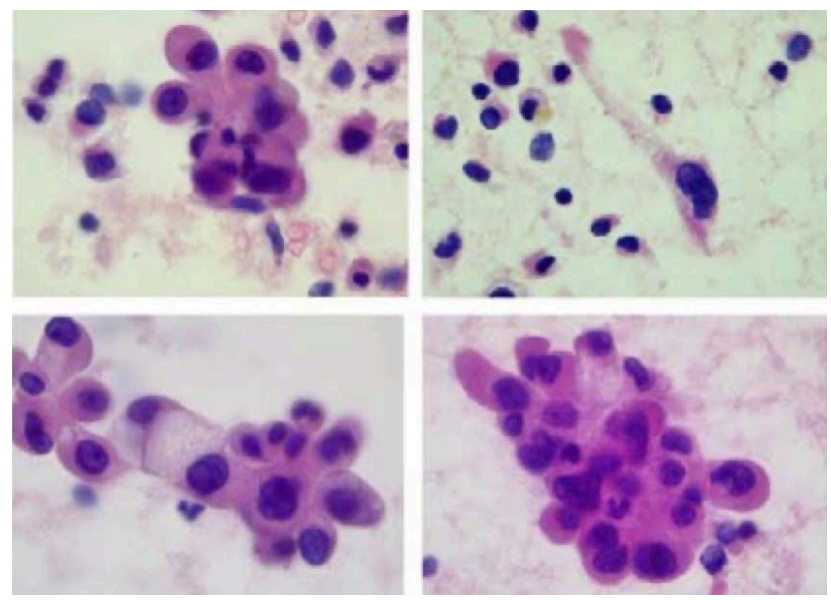

Figure 11. FNA biopsy showing classic hobnail variant features.
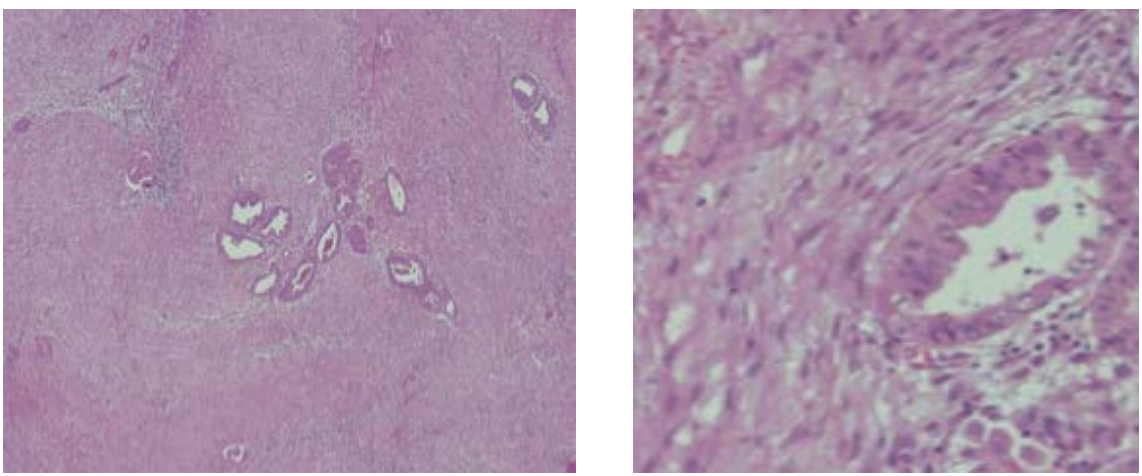

Figure 12. PTC with fasciitis-like stroma.

of myofibroblasts [85]. The importance of recognizing this variant is that they should not be confused with anaplastic carcinomas secondary to dedifferentiation of a conventional PTC, with diffuse sclerosing variant of PTC and with carcinosarcomas [57] [85] [86].

The definitive diagnosis of PTC is made on the basis of cellular and nuclear 
characteristics (cytological characteristics) with cells that adopt a cuboidal form with nuclear "grooving" and cytoplasmic inclusions [5] [8] [57] [58] [60]. PTC is characterized by multifocality in $18 \%$ to $85 \%$ of patients and is associated with an increased risk of lymph node metastasis [60] [62] [87] [88] [89]. Metastases to regional lymph nodes are quite common in patients with PTC at the time of initial diagnosis, with a frequency that varies between $30 \%$ to $80 \%$ of the cases [60] [90] [91] [92] [93]. Despite this rate of lymph node metastases, the 10-year survival rate remains $95 \%$ [14].

Combined PTC and medullary thyroid carcinoma (MTC) are rare, with an incidence of approximately $0.15 \%$ of all thyroid neoplasm [94] [95]. These tumors are made up of separate areas of cells with PTC or MTC [8] [57]. Immuno-staining for thyroglobulin and calcitonin helps to make the distinction of the two components.

Insular variant of PTC is distinguished by high cellularity with scant colloid, which forms well-defined nests (insulae) of monotonous round cells [96]. Some tumors have papillary differentiation, whereas others are categorized as a variant of follicular thyroid carcinoma (FTC). The average tumor size at presentation is greater than five centimeters [96], regional lymph node metastases are seen in more than $50 \%$ of patients, and up to $70 \%$ have distant metastases [97]. Insular variant is considered an intermediate grade tumor in a spectrum in between the conventional PTC and anaplastic thyroid carcinoma (ATC), it is associated with 30 -year cancer-specific mortality rate of $25 \%$ (versus $8 \%$ for classic PTC) [98].

\section{Molecular Markers in PTC}

RET/PTC rearrangement are found in roughly $5 \%$ to $80 \%$ of PTC with a highly variable depending on the geographic regions of the different research studies performed [57] [99]. Numerous fusions of the tyrosine kinase domain of RET have been reported with the RET/PTC1 been the most common followed by the RET/PTC3. In pediatric patients with PTC secondary to radiation exposure, the RET/PTC3 fusion is the dominant rearrangement [99].

Chromosomal rearrangements affecting the TRK gene are identified in approximately $10 \%$ of PTC, which arise from the fusion of tyrosine kinase domain of TRK on chromosome 1q22 to the tropomyosin gene [99]. Activating point mutations of the RAS proto-oncogene ensue in a very small proportion of PTC. The most frequent one is the N-RAS codon mutation. FVPTC has a greater incidence of RAS mutations than in other subtypes of PTC. Nevertheless, RAS mutations are also identified in follicular carcinomas and adenomas [99].

The BRAF mutation (V600E) has been recognized to be fairly limited to PTC and ATC and is very valuable in the differential diagnosis difficult thyroid neoplasms (Table 3). Regrettably the FVPTC has a BRAF mutation in only 5\% to $20 \%$ of the cases while classic PTC shows a BRAF mutation in approximately $35 \%$ to $70 \%$ of the cases [57] [99]. BRAF mutations have been shown to be predictive of tumor behavior and response to radioactive iodine [57] [99]. 
Table 3. Molecular markers in PTC [5] [57].

\begin{tabular}{cc}
\hline Mutation & Prevalence \\
\hline BRAF V600E & $45 \%$ \\
RET/PTC & $20 \%$ \\
Copy Gain PI3KCA & $12 \%$ \\
RAS & $10 \%$ \\
PTEN & $<10 \%$ \\
PI3KCA & $<10 \%$ \\
TRK rearrangements & \\
Beta catenin & \\
HMGA2 overexpression & \\
Insulin like growth factor II mRNA-binding protein 3 (IMP3)
\end{tabular}

Insulin-like growth factor II mRNA binding protein 3 (IMP3) and HMGA2 and are expressed during fetal development and then tissue levels are very low to absent in adult tissues. Current studies have identified that in many malignant neoplasms IMP3 and HMGA2 have elevated levels of expression [68] [100]. These studies have identified that normal thyroid tissues and follicular adenomas express low levels of HMGA2 and IMP3 mRNA compared to PTC. The levels of expression in PTC range from 1.5 to greater that ten-fold higher than in normal thyroid tissues or adenomas, so measurements of the levels by quantitative RT-PCR helps to separate benign from low grade PTC [68] [100]. These tactics should help the pathologist to utilize molecular methods in resolving difficult cases.

\section{Factors Influencing Prognosis}

Patient outcomes and primary tumor size are intimately associated with PTC. In a study by Bilimoria et al. [101] of 52,173 patients with PTC diagnosed between 1985 and 1998 from the National Cancer Data Base (NCDB), found that 10-year cumulative recurrence rates increased incrementally from 5\% for tumors less than $1 \mathrm{~cm}$ to $25 \%$ for tumors greater $8 \mathrm{~cm}$ and that cancer-specific mortality rates increased incrementally from $2 \%$ for tumors less than $1 \mathrm{~cm}$ to $19 \%$ for tumors greater than $8 \mathrm{~cm}$ indicating that the tumor size is intimately linked with PTC outcome, including higher rates of locoregional and distant metastases [89]. They also demonstrated a slightly better 10-year relative overall survival (OS) for total thyroidectomy as compared to thyroid lobectomy ( $98.4 \%$ vs. $97.1 \%$, respectively, $\mathrm{p}<0.05)$. Nonetheless, data on extrathyroidal extension, completeness of resection, and other comorbid conditions, which could have had a major impact on survival and recurrence risk, were not available. Adam et al. [102] completed an updated analysis of 61,775 patients in the NCDB who underwent thyroid surgery between 1998 and 2006. They demonstrated that the OS advantage seen 
for patients with PTC between $1 \mathrm{~cm}$ to $4 \mathrm{~cm}$ who underwent thyroidectomy in the study by Bilimoria et al. [89] disappeared when further adjustment was made for additional variables related to complexity and severity of illness.

In nearly $30 \%$ of patients extrathyroidal extension can be identified by central compartment dissection [14] [103]. This is linked with a higher risk of recurrent or persistent disease [104], an increased likelihood of regional lymph node metastases [105], and reduced OS [89], as compared to patients without extrathyroidal spread. Gross extrathyroidal extension identified at the time of surgery is seen in up to $9 \%$ of patients [106] [107]. Invasion into the surrounding structures (musculature, esophagus, or trachea) has been associated with elevated recurrence rates and reduced OS [106] [107], and in this settings they may benefit from external beam radiotherapy [108] after aggressive surgery [109] [110].

Prognosis may be affected by tumor multifocality and bilaterality. PTC localized to one thyroid lobe has a roughly $45 \%$ chance of having PTC in the contralateral lobe [60]. This is one of the motives why recurrence rates have been reported to be slightly higher in patients treated with thyroid lobectomy although recent data have demonstrated that in properly selected patients, clinical outcomes are very similar following unilateral or bilateral thyroid surgery [111] [112] [113] [114] [115]. Perrino et al. [104] reported that tumor multifocality was related to a higher risk of persistent or recurrent disease, even in patients managed with total thyroidectomy. In patients with papillary thyroid microcarcinomas (PTMC) tumor multifocality has also been found. The only risk factors significantly influencing recurrence rates in patients with PTMC were the number of histologic foci and the extent of initial thyroid surgery [13].

Regional lymph node metastases can be identified at the time of the operation in as many as $53 \%$ of patients with PTC [116]. Nevertheless, the incidence rates vary substantially, depending on the mode of detection. Prophylactic central compartment dissections yield high rates of lymph node micro-metastases (53\% to 65\%) [92] [116], whereas macro-metastases, when lymph node metastases are discovered by preoperative ultrasound or during surgery, are found in approximately $30 \%$ to $40 \%$ of patients [107]. The magnitude of neck ultrasound on the management of PTC was emphasized by a study in which patients with preoperative positive lateral compartment regional lymph node metastasis on ultrasound had considerably worse lymph node recurrence-free survival (RFS) as compared to patients without preoperatively detectable lateral compartment lymph node metastases [117]. Patients who did not have lymph node metastases on neck ultrasound before surgery obtained no benefit in terms of RFS when prophylactic neck dissection was performed [117]. Additional series have confirmed that lymph node macro-metastases identified by ultrasound are related with lower RFS for patients PTMC [118]. There is an inverse relationship between the number of grossly involved lymph nodes and RFS, however the impact of metastatic disease to regional lymph nodes on cancer-specific survival is less clear [118]. Numerous studies have not been able to establish that lymph 
node metastasis increase mortality rates, while other studies have shown reduced OS [119]. The discrepancy among series regarding the effect of metastatic disease to regional lymph node on mortality may be explained through a probe of the SEER database in which patient age at the time of lymph node surgery was scrutinized; those over age 45 years with lymph node involvement had a $46 \%$ increased risk of death as compared with similarly aged patients without lymph node metastases. In contrast, in patients less than age 45 years with lymph node metastases there was no effect on survival [120].

The prognosis of patients with PTC is associated to age, gender, and stage (Table 3). In general, the life expectancy is minimally affected if the cancer does not extend beyond the thyroid. Prognosis is better in females and in patients younger than 40 years. The survival rate is at least $95 \%$ with appropriate treatments. If PTC is not managed appropriately, it may result in symptoms because of compression and/or infiltration of the tumor into the surrounding tissues, and the cancer may metastasize to lung and bone. Metastases, in descending order of frequency, are most common in the regional lymph nodes and lung, followed by the bone, brain, liver, and other sites. As mentioned previously the metastatic potential seems to be related to the tumor size. A study by $\mathrm{Yu}$ et al. identified that PTMC are generally associated with an excellent prognosis; however, roughly $0.5 \%$ of patients with PTMC may die [121]. Table 4 shows the risk factors for OS.

\section{Diagnosis}

PTC is diagnosed as an incidentaloma in the preponderance of cases during imaging studies (ultrasonography, computed tomography, positron emission tomography, or magnetic resonance imaging) performed for reasons unrelated to the thyroid gland [5]. The bulk of patients with PTC have no specific symptoms and the results of these incidentalomas will trigger a diagnostic evaluation. The initial sign is often the finding of a new thyroid nodule, an increase in size of a previously detected nodule, pain resulting from hemorrhage within a nodule, or palpable cervical [5] [58]. Symptoms that often predict poor prognosis include dysphagia, dysphonia, or dyspnea since they are the result of local invasion and are usually due to undifferentiated thyroid cancer, since differentiated tumors rarely invade surrounding structures [5] [122].

Table 4. Risk factors for OS [56].

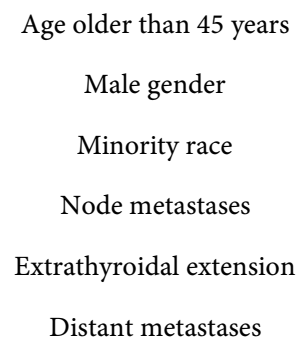


The clinical importance of thyroid nodules lies in the need to rule out thyroid cancer, which occurs between $7 \%$ and $15 \%$ of cases, fluctuating according to age, gender, radiation exposure history, and family history [122] [123]. The prevalence of palpable thyroid nodules in the general population is roughly $5 \%$ to $7 \%$ in women and $1 \%$ in men living in parts of the world with sufficient iodine [5] [124] [125]. In contrast, high-resolution neck and thyroid ultrasound can detect thyroid nodules in approximately $19 \%$ to $68 \%$ of randomly selected people, with higher frequencies in women and the elderly [122] [126].

If a thyroid nodule larger than $1 \mathrm{~cm}$ in any diameter is identified, a serum level of thyroid stimulating hormone (TSH) should be obtained (recommendation 2 ATA) [56]. When the TSH is low, a thyroid scan should be performed (which is the only indication today to perform this study) to record if the thyroid nodule is hyper-functional ("hot", that is, the uptake of the marker is greater than the normal thyroid), isofuncionante ("warm", that is, the uptake of the marker is equal to the surrounding thyroid) or none functioning ("cold", that is, it has a lower uptake than the thyroid tissue) [5] [56] [127]. Since hyper-functional thyroid nodules seldomly contain cancer, if one that matches to the nodule in question is found, a cytological evaluation is not necessary [5] [56]. High serum levels of TSH, even within high ranges of normality, are associated with an increased risk of malignancy in the thyroid nodule, as well as a more advanced stage of thyroid cancer [5] [128] [129].

In the initial assessment of thyroid nodules, it is not recommended to regularly obtain serum thyroglobulin (Tg) (ATA recommendation 3) [56]. Tg levels may be elevated in the majority of thyroid diseases (benign and malignant) and is an insensitive and nonspecific test for thyroid cancer [130] [131]. The value of serum calcitonin in the assessment of thyroid nodules has been assessed in prospective non-randomized studies [5] [129] [132] [133] [134] [135], with mixed results, therefore, the ATA cannot recommend either for or against the measurement Routine serum calcitonin in patients with thyroid nodules (ATA recommendation 4) [56].

High-resolution neck and thyroid ultrasound should be completed in all patients suspected of having thyroid nodules, nodular goiter, or any radiographic abnormality that suggests a thyroid nodule detected incidentally in another imaging study (computed tomography or magnetic resonance imaging or 18FDG-PET) (ATA recommendation 6) [56]. Ultrasound of the neck and thyroid should assess the following characteristics [56]: the thyroid parenchyma (if homogeneous or heterogeneous), the size of the thyroid gland, the size, location, and ultrasonographic characteristics of any nodule, and finally the presence or absence of suspicious cervical lymph nodes in the central or lateral compartments [5] [56] [58] [129]. Table 5 shows the characteristics that should be assessed in the high-resolution neck and thyroid ultrasound.

Associated ultrasound characteristics in a thyroid nodule that increases the risk of malignancy, and combined with the size of the nodule, guides decision 
making (Table 6). The ultrasound characteristics the confer a high suspicion of malignancy includes solid, hypoechoic nodules, or nodules with mixed components (solid hypoechoic and partially cystic nodule) with one or more of the following features: irregular margins (infiltrative, micro-lobulated), microcalcifications, higher form than wide, calcifications at the edge of the cyst, evidence of extra thyroid extension [138] [139] [140].

Table 5. The characteristics that should be assessed in the ultrasound [5] [136] [137].

- Location (example-right upper lobe/if anterior or posterior)

- Nodule size (in three dimensions)

- Category of the ultrasonographic characteristics of the thyroid nodule:

o Composition of the nodule:

- Solid, cystic or spongiform

o Echogenicity:

- Isoechoic, hyperechoic, hypoechoic

o Margins:

- Regular

- Irregular

- Defined as infiltrative, micro-lobulated or spiculated

o Presence and type of calcifications:

- Marco-calcifications or microcalcifications

o Shape:

- If the nodule is taller than wide

o Vascularity:

- Central or peripheral

Table 6. Ultrasonographic patterns of thyroid nodules, estimated risk of malignancy, and management guide for thyroid nodules with FNAB [5] [56] [129] [138].

\begin{tabular}{|c|c|c|c|}
\hline $\begin{array}{l}\text { Ultrasonographic } \\
\text { Pattern }\end{array}$ & Ultrasonographic Characteristics & $\begin{array}{l}\text { Estimated Risk of } \\
\text { Malignancy }\end{array}$ & Size to perform FNAB \\
\hline High Risk & $\begin{array}{l}\text { Hypoechoic, solid nodules, or nodules with mixed components } \\
\text { (solid and partially cystic hypoechoic nodule) with one or more } \\
\text { of the following characteristics: irregular margins (infiltrative, } \\
\text { microlobed), microcalcifications, taller than wide, calcifications } \\
\text { on the edge of the cyst, evidence of extra thyroid extension }\end{array}$ & $\begin{array}{c}\text { Greater than } \\
70 \%-90 \%\end{array}$ & $\begin{array}{l}\text { FNAB is recommended if its } \\
\text { dimensions are equal to or } \\
\text { greater than } 1.0 \mathrm{~cm}\end{array}$ \\
\hline Intermediate Risk & $\begin{array}{l}\text { Hypoechoic solid nodule with smooth (regular) margins without } \\
\text { microcalcifications, no evidence of extra thyroid extension, } \\
\text { and the shape is not taller than wide }\end{array}$ & $10 \%$ al $20 \%$ & $\begin{array}{l}\text { FNAB is recommended if its } \\
\text { dimensions are equal to or } \\
\text { greater than } 1.0 \mathrm{~cm}\end{array}$ \\
\hline Low Risk & $\begin{array}{l}\text { Isoechoic or hyperechoic solid nodule, or partially cystic nodule } \\
\text { with eccentric solid areas, no microcalcification, no irregular margin, } \\
\text { no evidence of extra thyroid extension, no taller than wide }\end{array}$ & $5 \%$ al $10 \%$ & $\begin{array}{l}\text { FNAB is recommended if its } \\
\text { dimensions are equal to or } \\
\text { greater than } 1.5 \mathrm{~cm}\end{array}$ \\
\hline Very Low Risk & $\begin{array}{l}\text { Spongiform or partially cystic nodules without any of the } \\
\text { ultrasonographic features described in low, intermediate, } \\
\text { or high suspicion patterns }\end{array}$ & Less than $3 \%$ & $\begin{array}{l}\text { FNAB can be considered if its } \\
\text { dimensions are equal to or } \\
\text { greater than } 2.0 \mathrm{~cm} \\
\text { Observation without BAAF } \\
\text { is also reasonable }\end{array}$ \\
\hline Benign & Purely cystic nodules (without solid component) & Less than $1 \%$ & Do not perform FNAB \\
\hline
\end{tabular}


The most precise and cost-effective method for assessing thyroid nodules is fine needle aspiration biopsy (FNAB) (ATA recommendation 7) [5] [56] [129] [139] [140] [141]. Thyroid nodules with a higher probability of obtaining a non-diagnostic cytology (cystic component greater than $25 \%$ to $50 \%$ ) or a sampling error (nodules difficult to palpate or located in the posterior portion of the thyroid lobe), it is preferred to perform a FNAB guided by ultrasound [56] [129] [142] [143].

Non-diagnostic or unsatisfactory FNABs (Bethesda 1) are those that do not meet the quantitative or qualitative requirements established to say that the cytological assessment is adequate (i.e., the presence of at least six groups of well-visualized follicular cells, each group containing at least ten well-preserved epithelial cells, preferably in a single lamella) [143] [144] [145]. When a BAAF is performed in a thyroid nodule and the cytology result is non-diagnostic, the BAAF should be repeated with the support of ultrasound, and if available, the cytological evaluation should be performed at the time of the FNAB (recommendation 10 of the ATA) [56] [129] [144] [145] [146]. It has been suggested that FNAB should be repeated no earlier than three months after the initial FNAB to avoid a falsely positive interpretation due to biopsy-induced reactive changes [147]. Two recent studies have questioned the need for a waiting period of three months after the first FNAB because they found no correlation between the diagnostic performance and accuracy of the second FNAB and the waiting time between procedures [148] [149]. The ATA tells us that a waiting period of three months after a non-diagnostic biopsy is likely not necessary [56] [129]. Thyroid nodules that have had multiple FNABs that turned out to be non-diagnostic without having a highly suspected ultrasonographic pattern may be recommended observation vs. surgical excision to have a definitive histopathological diagnosis (ATA recommendation 10) [56].

In published series of patients classified according to the Bethesda system, non-diagnostic samples constituted $2 \%$ to $16 \%$ of all FNAB samples, of which $7 \%$ to $26 \%$ were resected [129] [150] [151]. The frequency of malignancy among all FNABs initially rated as non-diagnostic was $2 \%$ to $4 \%$ and among the nondiagnostic samples that were finally resected the frequency of malignancy $9 \%$ to 32\% [129] [150] [151] [152] [153].

If the thyroid nodule is benign in cytology after a FNAB (Bethesda 2), no extra diagnostic studies or immediate treatment are required (ATA recommendation 11) [56] [129]. Although prospective studies are lacking, the rates of malignancy in the retrospective series range from $1 \%$ to $2 \%$ [138] [153] [154] [155].

FNAB categorized as atypia of undetermined significance or follicular lesion of undetermined significance (Bethesda 3), is characterized by having specimens containing cells with architectural and/or nuclear atypia that are more prominent than expected for benign changes, but not sufficient for be located in one of the highest risk diagnostic categories [5] [56] [129] [138] [152]. In the studies that used the criteria established by the Bethesda System, the risk of cancer for 
patients with atypical nodules of undetermined significance or follicular lesion of undetermined significance who underwent surgery was $6 \%$ to $18 \%$ if NIFT (follicular thyroid neoplasia Non-invasive with papillary nuclear characteristics) is not considered as cancer, and $10 \%$ to $30 \%$ if NIFT is considered as a cancer [5] [56] [129] [138] [152].

For thyroid nodules with atypical cytology of undetermined significance or follicular lesion of undetermined significance after a FNAB, with worrying clinical and ultrasonographic characteristics, the assessment can be continued by repeating the BAAF or if you have the availability of molecular tests to complement the risk assessment of malignancy instead of proceeding directly with either a surveillance strategy or diagnostic surgery (lobectomy) [5] [56] [129] [138] [152]. Patient inclination should be considered in decision making (recommendation 15 of the ATA) [56]. If the FNAB is not repeated, and molecular tests are not performed, or both studies proved inconclusive, a diagnostic surgical excision can be performed for thyroid nodules with Bethesda 3 classification, according to clinical risk factors, ultrasound pattern and patient preference (ATA recommendation 15) [56].

The diagnostic category of the Bethesda 4, follicular neoplasm/suspected cytology of follicular neoplasm is used for cellular aspirates: composed of follicular cells arranged in an altered architectural pattern categorized by cell crowding and/or microfilm formation, lacking nuclear characteristics of papillary carcinoma or compounds almost exclusively of oncocytic cells (Hurthle) [5] [56] [129] [138] [152].

This is an intermediate risk category of malignancy in the Bethesda system, with an estimated risk of malignancy between $10 \%$ to $40 \%$ if NIFT is not considered as cancer and between $25 \%$ to $40 \%$ if NIFT is considered as cancer [5] [56] [129] [138] [152]. This category represents $1 \%$ to $25 \%$ (mean, $10 \%$ ) of all FNAB samples [56].

Diagnostic excision (lobectomy) is the long-established benchmark for the treatment of thyroid nodules with Bethesda IV cytology. However, today if the technology is taken into account, after taking into account the clinical assessment and ultrasonographic characteristics, molecular tests can be used to complement the assessment of the risk of malignancy rather than proceed directly with surgery (recommendation 16 of the ATA) [56]. Patient preference should be considered in clinical decision making. If molecular tests cannot be performed or are undetermined, surgical removal can be considered for the definitive diagnosis of thyroid nodules classified as Bethesda IV (ATA recommendation 16) [56].

The diagnostic category of the Bethesda V system, suspected cytology for malignancy embodies $1 \%$ to $6 \%$ of all FNABs, is set aside for aspirates with cytological characteristics that spawn a high suspicion of malignancy (mainly for papillary thyroid carcinoma) but that they are not sufficient for a conclusive diagnosis [5] [56] [129] [138] [152]. This is the category with the highest risk of undetermined cytology in the Bethesda System, with a projected cancer risk of $45 \%$ to 
$60 \%$ if NIFT is not considered as cancer and $50 \%$ to $75 \%$ if NIFT is considered as cancer [5] [56] [129] [138] [152]. Due to the high risk of cancer, the diagnosis of suspicious papillary carcinoma is an indication for surgery [56].

If the FNAB results in a suspicious cytology for papillary thyroid carcinoma, surgical treatment should be very similar to the management of a frankly reported FNAB. Factors that we must take into account in offering the definitive treatment with a suspicious cytology for papillary thyroid carcinoma, are the clinical risk factors, the ultrasonographic characteristics, the patient's preference and possibly the results of the molecular tests (BRAF, RAS, RET/PTC, PAX8/ PPAR) (ATA recommendation 17) [56].

If the cytological result is a diagnosis of primary thyroid malignancy, Bethesda VI, surgery is generally recommended (ATA recommendation 12) [56]. A diagnostic cytology of primary thyroid malignancy will almost always lead to thyroid surgery. However, in some parts of the world under active research protocol active surveillance can be offered as an alternative to immediate surgery in certain patients who meet some very specific criteria [129] [156] [157]:

- Patients with very low risk tumors (for example, papillary microcarcinomas without clinically evident metastases or local invasion, and without convincing cytological evidence of aggressive disease).

- Patients with high surgical risk due to multiple comorbidities.

- Patients with a relatively short lifespan (for example, severe cardiopulmonary disease, other malignant diseases, very old age).

- Patients with concurrent medical or surgical problems that must be addressed before thyroid surgery.

\section{Dynamic Risk Stratification for Thyroid Cancer}

Instead of using information that is only obtainable at one point in time, the new risk stratification models in thyroid cancer highlight the importance of dynamic risk assessment, where the initial assessment is changed over time as new information becomes accessible. These dynamic risk assessments models allow us to integrate response to therapy with the underlying individual tumor biology, to offer real-time risk assessments at any point in the course of the patient's disease [158].

The modern view of risk stratification begins with the detection of a suspicious thyroid nodule (peri-diagnostic period) [158]. It continues through the stages of diagnosis, treatment, adjuvant therapy, and follow-up. From a real-world perspective, in the postoperative period the eighth edition of the American Joint Committee on Cancer/tumor node metastasis (AJCC/TNM) staging system helps to predict disease-specific mortality. The American Thyroid Association (ATA) modified risk stratification system helps to predict the risk of recurrent or persistent disease [56]. These initial risk estimates are then revised over time using the descriptions from the ATA guidelines to define the patient's response to therapy at any point during follow-up (Table 7). 
Table 7. ATA guidelines classification of the patient's response to therapy [56].

- Excellent:

- No evidence of persistent/recurrent disease

- Biochemically incomplete:

- Abnormal thyroglobulin ( $\mathrm{Tg}$ ) or rising Tg antibodies in the absence of identifiable structural disease

- Structurally incomplete:

- Structural evidence of persistent/recurrent disease

- Indeterminate:

- Nonspecific findings that cannot be confidently classified as benign or malignant

These modified risk estimates are used to plan ongoing treatment. Lately, the move toward deferred intervention (active surveillance) of very low-risk thyroid cancers and a more minimalistic approach to thyroid surgery has expanded the risk-stratification sphere to include not only the intraoperative and postoperative time periods but also the peri-diagnostic period that initiates with the discovery of a suspicious thyroid nodule. In this peri-diagnostic time period it is key to identify low-risk thyroid cancers that may be treated appropriately with either an active surveillance management approach (with or without cytological confirmation) or for a minimalistic surgical intervention, such as thyroid lobectomy without neck dissection. Conversely, it is similarly imperative to identify, in the peri-diagnostic period, those patients who would be most likely to benefit from more aggressive initial interventions that could include a total thyroidectomy, with or without prophylactic or therapeutic neck dissection, radioactive iodine treatment, external beam radiation or upfront systemic therapy [158].

It is essential to recognize that highly sensitive disease-detection tools that can often detect small foci of PTC that may not require immediate diagnosis and management. The ATA guidelines provide numerous examples where an observational management approach, often without cytologic confirmation of the disease process is recommended as the preferred or alternative treatment approach to small-volume disease [56]:

An active surveillance treatment approach is acceptable for carefully selected patients with either:

- Highly suspicious sub-centimeter asymptomatic thyroid nodules without the need for cytologic confirmation.

- Biopsy-proven very low-risk thyroid cancers, such as intra-thyroidal PTMC:

- In locations not adjacent to the trachea or neurovascular structures without evidence of lymph node metastasis.

- Likewise, an observational management approach is also allowed for patients with:

- Persistent/recurrent small abnormal cervical lymph nodes

- Asymptomatic stable or slowly growing distant metastasis

- Stable or declining abnormal $\mathrm{Tg}$ or $\mathrm{Tg}$ antibodies

As it is clear that not all detectable findings require a speedy diagnostic or 
therapeutic intervention, it is crucial that we create a risk-stratification decision-making framework to differentiate actionable findings from non-actionable findings. Whether considering a highly suspicious sub-centimeter thyroid nodule without cytologic confirmation of disease, a biopsy-proven thyroid nodule with low-risk thyroid cancer, or persistent/recurrent disease in the neck or somewhere else, it useful to consider five key factors that when taken together, permit us to predict the probability that a specific tumor focus represents clinically actionable disease that may require further evaluations, ongoing observation, or therapeutic intervention [158]. Together tumor size and tumor location are major factors that determine whether a tumor focus is likely to cause clinically significant invasion into local structures, such as the recurrent laryngeal nerve, airway, gastrointestinal tract, major vessels, or other important structures. Another crucial factor is the tumor growth rate, measured as tumor volume doubling time, with an observational management approach being much more appropriate for tumors either, predicted to have a slow tumor growth rate, actual recorded slow growth rates over time, or tumors that are either symptomatic or likely to have symptomatic progression would be considered actionable. Patient inclination plays a crucial role when determining whether a specific lesion is actionable or non-actionable as it is imperative to incorporate the patient's grasp of the risks and benefits of intervention vs. observation with their value system and goals, in addition to offering early guidance as to whether the detectable lesion is actionable at the time of detection, ongoing re-evaluation of these same factors using the simple concepts of dynamic-risk stratification, that can help the clinician in the determining when it is time to transition from an active surveillance approach to an active management approach [158].

Dynamic-risk stratification commences as soon as a suspicious thyroid nodule is identified utilizing a peri-diagnostic risk-stratification system that incorporates tumor imaging features, medical team characteristics, and patient preferences to risk stratify patients as ideal, appropriate, or inappropriate for minimalistic initial treatment options, such as active surveillance or thyroid lobectomy. This clinical framework tackles the basic factors that distinguish actionable from non-actionable disease [158].

Patients with small, asymptomatic thyroid nodules, typically $\leq 1 \mathrm{~cm}$ maximal diameter, $1 \mathrm{~cm}^{3}$, or $1 \mathrm{~mL}$ volume, confined to the thyroid gland and surrounded by normal thyroid parenchyma can be monitored with active surveillance with or without cytologic confirmation, especially in patients who appreciate their normal thyroid function and who wish escaping thyroid surgery [56]. Patients who have tumors larger than $1.5 \mathrm{~cm}$ to $2.0 \mathrm{~cm}$, tumors in sub-capsular locations adjacent to important structures (such as the trachea and recurrent laryngeal nerve), tumors with documented growth rate doubling times of less than two-years are usually deemed unsuitable for observation and would be regarded to have actionable disease. If the tumor growth rate is undetermined at the time of nodule discovery, then this can be established with serial ultrasound examinations 
performed roughly every six months for one to two years. The regularity of ultrasound examinations and long-term follow-up depends on the tumor size, tumor location, and the ascertained growth rate. With the use of this concept active surveillance continues until there is a three-millimeter increase in tumor diameter which represents a $100 \%$ growth in tumor volume. The detection of metastatic disease or the direct extension of the tumor into surrounding structures of the thyroid gland will lead to discontinue active surveillance based on patient preference [158].

This risk-stratified, minimalistic treatment approach to very low-risk thyroid cancers has been proven to be safe and successful over 5 to 10 years of follow-up in studies from Japan, Korea, and the United States [56] [159] [160]. In the first 10 years of active surveillance only $2 \%$ to $8 \%$ of PTMC enlarge $\geq 3 \mathrm{~mm}$ in maximum diameter, $12 \%$ to $14 \%$ will show and an increase in tumor volume of greater than $50 \%$ (which is the minimum change in a thyroid nodule volume that can be reproducibly measured) and new regional lymph node metastases are identified in $2 \%$ to $4 \%$ of the cases. The probability of disease progression is greater in younger patients than in older patients. One important thing to tell the patient that is critical in decision making for the patient is that at the time of disease progression delayed surgical intervention is fairly efficacious with superb outcomes and no disease-specific mortality.

The ATA guidelines now acknowledge a minimalistic surgical approach (thyroid lobectomy without neck dissection) to manage intra-thyroidal PTC less than $4 \mathrm{~cm}$ in appropriately selected patients [56]. Meticulous peri-diagnostic, preoperative, and intra-operative risk stratification are the bases for effective use of thyroid lobectomy without needing to perform an undesirable rate of early-completion thyroidectomies. Patients classified as being ideal for thyroid lobectomy would have PTMC that are confined to the thyroid gland in the scenario of an otherwise normal thyroid on ultrasound and clinically negative neck. Patients are categorized as appropriate for lobectomy if the tumor is 1 to $4 \mathrm{~cm}$ in maximum diameter if the contralateral lobe is entirely normal or if there are other irregularities on ultrasound, such as thyroiditis or benign-appearing nodules (again, in the setting of the clinically negative neck). Patients with extra-thyroidal extension, clinical N1 disease, or distant metastasis would be considered inappropriate for thyroid lobectomy as initial management option.

In addition to the significance of peri-diagnostic and preoperative risk stratification with respect to the selection of thyroid lobectomy as primary management option, it is imperative to acknowledge that there are intra-operative findings that could modify the initial management option and lead to an immediate total thyroidectomy. We urge patients to find a surgeon who they trust and to authorize him or her to make a final assessment in the operating room concerning the initial extent of surgery that should be carry out (this can vary from lobectomy to total thyroidectomy, with or without neck dissection) [56] [158].

Nonetheless, even with a proper preoperative and intra-operative risk stratifi- 
cation as many as $6 \%$ to $20 \%$ of patients will have unforeseen findings on the final pathology results that may lead to a completion thyroidectomy and typically, radioactive iodine. An added 5\% to $10 \%$ may require at some point in time a completion thyroidectomy during follow-up for diagnostic or therapeutic purposes. The frequency of early-completion thyroidectomy, carry out following analysis of the initial pathology report, will vary depending on how aggressive each management team is with regard to the use of radioactive iodine for either remnant ablation or adjuvant treatment. If minor factors, such as minor extra-thyroidal extension, very small-volume lymph node metastasis, or small tumors with aggressive histologic features frequently lead to the use of radioactive iodine therapy then the completion thyroidectomy rate may be as high as $20 \%$ [56] [158]. The most frequent cause for a completion thyroidectomy is unexpected, the extensive vascular invasion that could not be visualized preoperatively or intra-operatively. As a result of these, patients need to comprehend that the final determination of whether a thyroid lobectomy is the appropriate initial management approach can only be attained by the incorporation of preoperative, intra-operative, and postoperative risk stratification [56] [158].

The guidelines for the staging of well-differentiated PTC underwent considerable changes, including an increase of the age cutoff from 45 years to 55 years at diagnosis, elimination of microscopic extra-thyroidal extension as a crucial component of the staging system, no longer requiring allocation of stage III to older patients with microscopic extra-thyroidal extension or lymph node metastases, creation of a new T3b category for tumors of any size that exhibit gross extra-thyroidal extension involving only the surrounding strap muscles [56] [158]. The AJCC Differentiated Thyroid Cancer Committee cautiously studied the possibility of incorporating the use of molecular markers (specifically, BRAF ${ }^{\mathrm{V} 600 \mathrm{E}}$ and TERT promoter mutations) in the AJCC prognostic staging definitions. While both of these mutations, especially when present at the same time have been proven to be prognosticators of poor clinical outcomes, they showed to add only a minimal benefit to the conventional anatomic staging factors. Consequently, molecular classification of differentiated PTC, while providing some prognostic information, were not compelling enough to warrant upstaging of PTC to prognostic stages beyond those mandated by TNM risk factors. Nevertheless, analogous to the method used in the ATA risk-stratification system, molecular results can be used to enhance and individualize risk within the risk groups or stages. The three critical factors that determine the prognostic staging groups of the eighth edition AJCC/TNM cancer staging system include the age at diagnosis, the presence or absence of distant metastases, the presence or absence of gross extra-thyroidal extension [56] [158].

In the eighth edition of the AJCC/TNM cancer staging system it was foreseen that the preponderance of patients would be categorized as stage I or stage II exhibiting the excellent outcomes expected in the majority of PTC patients. A minor number of patients particularly the older patients with either distant metas- 
tases or gross extra-thyroidal extension were predicted to do worse and are consequently classified as stage III or IV [56] [158].

\section{Conclusion}

PTC accounts for roughly $89 \%$ of all thyroid malignancies. Some subtypes of PTC such as tall cell and columnar cell variants seem to have a more aggressive biological course. PTC is a multifaceted and often unpredictable disease that necessitates numerous management tools and careful analysis of the patient's response to therapy, which in the final consideration is the key to the patient's long-term outcome. The noticeable increase in the prevalence and incidence of PTC over the last 10 to 20 years has required a re-assessment of the conventional one-size-fits-all approach to its diagnosis and management. The conversion to more individualized management has led to a much more risk-adapted approach to the diagnosis, initial therapy, adjuvant therapy, and follow-up of patients with PTC.

\section{Conflicts of Interest}

The authors declare no conflicts of interest regarding the publication of this paper.

\section{References}

[1] Howlader, N., Krapcho, M., et al. (2018) SEER Cancer Statistics Review, 1975-2014. National Cancer Institute, Bethesda.

[2] Nagataki, S. and Nystrom, E. (2002) Epidemiology and Primary Prevention of Thyroid Cancer. Thyroid, 12, 889-896. https://doi.org/10.1089/105072502761016511

[3] Cardis, E., Howe, G., Ron, E., Bebeshko, V., Bogdanova, T., Bouville, A., et al. (2006) Cancer Consequences of the Chernobyl Accident: 20 Years on. Journal of Radiological Protection, 26, 127-140. https://doi.org/10.1088/0952-4746/26/2/001

[4] Bower, J.M. (1996) What Will Save Neuroscience? Neuroimage, 4, S29-S33. https://doi.org/10.1006/nimg.1996.0047

[5] Arrangoiz, R., Cordera, F., Caba, D., Moreno, E., Luque-de-Leon, E. and Muñoz, M. (2019) Thyroid Cancer. International Journal of Otolaryngology and Head \& Neck Surgery, 8, 217-270. https://doi.org/10.4236/ijohns.2019.86024

[6] Davies, L. and Welch, H.G. (2014) Current Thyroid Cancer Trends in the United States. JAMA Otolaryngology—Head \& Neck Surgery, 140, 317-322. https://doi.org/10.1001/jamaoto.2014.1

[7] Khan, A.N.V. (2010) Endocrine Pathology: Differential Diagnosis and Molecular Advances. 2nd Edition, Springer, New York.

[8] DeLellis, R.A., Heitz, P.U. and Eng, C. (2004) Pathology and Genetics of Tumours of Endocrine Organs. World Health Organization Classification of Tumours, IARC Press, Lyon.

[9] Grubbs, K.L. (2019) Carcinoma of the Thyroid Gland and Neoplasms of the Parathyroid Glands. In: Barry, M. and Feig, W., Eds., The MD Anderson Surgical Oncology Handbook, 6th Edition, Wolters Kluwer, Philadelphia.

[10] Toniato, A., Boschin, I., Casara, D., Mazzarotto, R., Rubello, D. and Pelizzo, M. 
(2008) Papillary Thyroid Carcinoma: Factors Influencing Recurrence and Survival. Annals of Surgical Oncology, 15, 1518-1522. https://doi.org/10.1245/s10434-008-9859-4

[11] Sciuto, R., Romano, L., Rea, S., Marandino, F., Sperduti, I. and Maini, C.L. (2009) Natural History and Clinical Outcome of Differentiated Thyroid Carcinoma: A Retrospective Analysis of 1503 Patients Treated at a Single Institution. Annals of Oncology, 20, 1728-1735. https://doi.org/10.1093/annonc/mdp050

[12] Loh, K.C., Greenspan, F.S., Gee, L., Miller, T.R., Yeo, P.P.B. (1997) Pathological Tumor-Node-metastasis (pTNM) Staging for Papillary and Follicular Thyroid Carcinomas: A Retrospective Analysis of 700 Patients. Journal of Clinical Endocrinology \& Metabolism, 82, 3553-3562. https://doi.org/10.1210/jcem.82.11.4373

[13] Chow, S.M., Law, S.C.K., Chan, J.K.C., Au, S.K., Yau, S. and Lau, W.H. (2003) Papillary Microcarcinoma of the Thyroid-Prognostic Significance of Lymph Node Metastasis and Multifocality. Cancer, 98, 31-40. https://doi.org/10.1002/cncr.11442

[14] American Cancer Society (2018) Cancer Facts and Figures 2018. American Cancer Society, Atlanta.

[15] Cancer of the Thyroid Invasive: Trends in SEER Incidence and U.S. Mortality Using the Joinpoint Regression Program, 1975-2011(SEER) Stat version 8.1.2 Rate Session. https://seer.cancer.gov/

[16] Santoro, M. and Carlomagno, F. (2013) Central Role of RET in Thyroid Cancer. Cold Spring Harbor Perspectives in Biology, 5, Article ID: a009233.

https://doi.org/10.1101/cshperspect.a009233

[17] Legakis, I. and Syrigos, K. (2011) Recent Advances in Molecular Diagnosis of Thyroid Cancer. Journal of Thyroid Research, 2011, Article ID: 384213. https://doi.org/10.4061/2011/384213

[18] Prescott, J.D. and Zeiger, M.A. (2015) The RET Oncogene in Papillary Thyroid Carcinoma. Cancer, 121, 2137-2146. https://doi.org/10.1002/cncr.29044

[19] Musholt, T.J., Musholt, P.B., Khaladj, N., Schulz, D., Scheumann, G.F.W. and Klempnauer, J. (2000) Prognostic Significance of RET and NTRK1 Rearrangements in Sporadic Papillary Thyroid Carcinoma. Surgery, 128, 984-993. https://doi.org/10.1067/msy.2000.110845

[20] Wasenius, V.M., Hemmer, S., Karjalainen-Lindsberg, M.-L., Nupponen, N.N., Franssila, K. and Joensuu, H. (2005) MET Receptor Tyrosine Kinase Sequence Alterations in Differentiated Thyroid Carcinoma. American Journal of Surgical Pathology, 29, 544-549. https://doi.org/10.1097/01.pas.0000156103.37756.e2

[21] Colletta, G., Cirafici, A.M. and Di Carlo, A. (1989) Dual Effect of Transforming Growth Factor Beta on Rat Thyroid Cells: Inhibition of Thyrotropin-Induced Proliferation and Reduction of Thyroid-Specific Differentiation Markers. Cancer Research, 49, 3457-3462.

[22] Mathur, A., Moses, W., Rahbari, R., Khanafshar, E., Duh, Q.Y., Clark, O., et al. (2011) Higher Rate of BRAF Mutation in Papillary Thyroid Cancer Over Time: A Single-Institution Study. Cancer, 117, 4390-4395.

https://doi.org/10.1002/cncr.26072

[23] Xing, M., Alzahrani, A.S., Carson, K.A., Viola, D., Elisei, R., Bendlova, B., et al. (2013) Association between $B R A F$ V600E Mutation and Mortality in Patients with Papillary Thyroid Cancer. JAMA, 309, 1493-501. https://doi.org/10.1001/jama.2013.3190

[24] Liu, C., Chen, T. and Liu, Z. (2016) Associations between $\mathrm{BRAF}^{\mathrm{V} 600 \mathrm{E}}$ and Prognostic Factors and Poor Outcomes in Papillary Thyroid Carcinoma: A Meta-Analysis. 
World Journal of Surgical Oncology, 14, Article No. 241. https://doi.org/10.1186/s12957-016-0979-1

[25] Ron, E., Lubin, J.H., Shore, R.E., Mabuchi, K., Modan, B., Pottern, L.M., et al. (1995) Thyroid Cancer after Exposure to External Radiation: A Pooled Analysis of Seven Studies. Radiation Research, 141, 259-277. https://doi.org/10.2307/3579003

[26] Baker, S.R. and Bhatti, W.A. (2006) The Thyroid Cancer Epidemic: Is It the Dark Side of the CT Revolution? European Journal of Radiology, 60, 67-69. https://doi.org/10.1016/j.ejrad.2006.04.022

[27] Ronckers, C.M., Engels, E.A., Curtis, R.E., Freedman, D.M., Ron, E., Ries, L.A.G., Hacker, D.G., Edwards, B.K., Tucker, M.A. and Fraumeni Jr., J.F. (2006) New Malignancies among Cancer Survivors: SEER Cancer Registries, 1973-2000. New Malignancies Following Cancer of the Thyroid and Other Endocrine Glands, No. 05-5302, Bethesda, MD., 375-395.

[28] Williams, E.D., Abrosimov, A., Bogdanova, T., Demidchik, E.P., Ito, M., LiVolsi, V., et al. (2004) Thyroid Carcinoma after Chernobyl Latent Period, Morphology and Aggressiveness. British Journal of Cancer, 90, 2219-2224.

https://doi.org/10.1038/sj.bjc.6601860

[29] Brenner, A.V., Tronko, M.D., Hatch, M., Bogdanova, T. I., Oliynik, V.A., Lubin, J.H., et al. (2011) I-131 Dose Response for Incident Thyroid Cancers in Ukraine Related to the Chornobyl Accident. Environmental Health Perspectives, 119, 933-939. https://doi.org/10.1289/ehp.1002674

[30] Li, Z., Franklin, J., Zelcer, S., Sexton, T. and Husein, M. (2014) Ultrasound Surveillance for Thyroid Malignancies in Survivors of Childhood Cancer Following Radiotherapy: A Single Institutional Experience. Thyroid, 24, 1796-1805. https://doi.org/10.1089/thy.2014.0132

[31] Port, M., Boltze, C., Wang, Y., Röper, B., Meineke, V. and Abend, M. (2007) A Radiation-Induced Gene Signature Distinguishes Post-Chernobyl from Sporadic Papillary Thyroid Cancers. Radiation Research, 168, 639-649. https://doi.org/10.1667/RR0968.1

[32] Kikuchi, S., Perrier, N., Ituarte, P., Siperstein, A.E., Duh, Q.-Y. and Clark, O.H. (2004) Latency Period of Thyroid Neoplasia after Radiation Exposure. Ann Surg, 239, 536-543. https://doi.org/10.1097/01.sla.0000118752.34052.b7

[33] McDonald, T.A. (2002) A Perspective on the Potential Health Risks of PBDEs. Chemosphere, 46, 745-755. https://doi.org/10.1016/S0045-6535(01)00239-9

[34] Zuurbier, M., Leijs, M., Schoeters, G., Tusscher, G.T. and KOPPE, J.G. (2006) Children's Exposure to Polybrominated Diphenyl Ethers. Acta Paediatrica, 95, 65-70. https://doi.org/10.1080/08035320600886299

[35] Hooper, K. and McDonald, T.A. (2000) The PBDEs: An Emerging Environmental Challenge and Another Reason for Breast-Milk Monitoring Programs. Environmental Health Perspectives, 108, 387-392. https://doi.org/10.1289/ehp.00108387

[36] Hardell, L., Van Bavel, B., Lindström, G., Eriksson, M. and Carlberg, M. (2006) In Utero Exposure to Persistent Organic Pollutants in Relation to Testicular Cancer Risk. International Journal of Andrology, 29, 228-234. https://doi.org/10.1111/j.1365-2605.2005.00622.x

[37] Zhao, G., Jiang Wang, Z., Zhou, H. and Zhao, Q. (2009) Burdens of PBBs, PBDEs, and PCBs in Tissues of the Cancer Patients in the E-Waste Disassembly Sites in Zhejiang, China. Science of the Total Environment, 407, 4831-4837. https://doi.org/10.1016/j.scitotenv.2009.05.031

[38] Brindel, P., Doyon, F., Rachédi, F., Boissin, J.-L., Sebbag, J., Shan, L., et al. (2009) 
Anthropometric Factors in Differentiated Thyroid Cancer in French Polynesia: A Case-Control Study. Cancer Causes \& Control, 20, 581-590. https://doi.org/10.1007/s10552-008-9266-y

[39] Dal Maso, L., La Vecchia, C., Franceschi, S., Preston-Martin, S., Ron, E., Levi, F., et al. (2000) A Pooled Analysis of Thyroid Cancer Studies. V. Anthropometric Factors. Cancer Causes \& Control, 11, 137-144. https://doi.org/10.1023/A:1008938520101

[40] Kitahara, C.M., Pfeiffer, P.R., Sosa, J.A. and Shiels, M.S. (2019) Impact of Overweight and Obesity on U.S. Papillary Thyroid Cancer Incidence Trends (1995-2015). Journal of the National Cancer Institute, 112, 810-817. https://doi.org/10.1093/jnci/djz202

[41] Leitzmann, M.F., Brenner, A., Moore, S.C., Koebnick, C., Park, Y., Hollenbeck, A., et al. (2010) Prospective Study of Body Mass Index, Physical Activity and Thyroid Cancer. International Journal of Cancer, 126, 2947-2956. https://doi.org/10.1002/ijc.24913

[42] Berghofer, A., Pischon, T., Reinhold, T., Apovian, C.M., Sharma, A.M. and Willich, S.N. (2008) Obesity Prevalence from a European Perspective: A Systematic Review. BMC Public Health, 8, Article No. 200. https://doi.org/10.1186/1471-2458-8-200

[43] Wang, Y. and Beydoun, M.A. (2007) The Obesity Epidemic in the United States-Gender, Age, Socioeconomic, Racial/Ethnic, and Geographic Characteristics: A Systematic Review and Meta-Regression Analysis. Epidemiologic Reviews, 29, 6-28. https://doi.org/10.1093/epirev/mxm007

[44] Vriens, M.R., Suh, I., Moses, W. and Kebebew, E. (2009) Clinical Features and Genetic Predisposition to Hereditary Nonmedullary Thyroid Cancer. Thyroid, 19, 1343-1349. https://doi.org/10.1089/thy.2009.1607

[45] Musholt, T.J., Musholt, P.B., Petrich, T., Oetting, G., Knapp, W.H. and Klempnauer, J. (2000) Familial Papillary Thyroid Carcinoma: Genetics, Criteria for Diagnosis, Clinical Features, and Surgical Treatment. World Journal of Surgery, 24, 1409-1417. https://doi.org/10.1007/s002680010233

[46] Uchino, S., Ishikawa, H., Miyauchi, A., Hirokawa, M., Noguchi, S., Ushiama, M., et al. (2016) Age- and Gender-Specific Risk of Thyroid Cancer in Patients with Familial Adenomatous Polyposis. Journal of Clinical Endocrinology \& Metabolism, 101, 4611-4617. https://doi.org/10.1210/jc.2016-2043

[47] Charkes, N.D. (1998) On the Prevalence of Familial Nonmedullary Thyroid Cancer. Thyroid, 8, 857-858. https://doi.org/10.1089/thy.1998.8.857

[48] Alsanea, O., Wada, N., Ain, K., Wong, M., Taylor, K., Ituarte, P.H.G., et al. (2000) Is Familial Non-Medullary Thyroid Carcinoma More Aggressive than Sporadic Thyroid Cancer? A Multicenter Series. Surgery, 128, 1043-1050.

https://doi.org/10.1067/msy.2000.110848

[49] Mitro, S.D., Rozek, L.S., Vatanasapt, P., Suwanrungruang, K., Chitapanarux, I., Srisukho, S., et al. (2016) Iodine Deficiency and Thyroid Cancer Trends in Three Regions of Thailand, 1990-2009. Cancer Epidemiology, 43, 92-99.

https://doi.org/10.1016/j.canep.2016.07.002

[50] Negri, E., Dal Maso, L., Ron, E., La Vecchia, C., Mark, S.D., Preston-Martin, S., et al. (1999) A Pooled Analysis of Case-Control Studies of Thyroid Cancer. II. Menstrual and Reproductive Factors. Cancer Causes \& Control, 10, 143-155. https://doi.org/10.1023/A:1008880429862

[51] Franceschi, S., Preston-Martin, S., Dal Maso, L., Negri, E., La Vecchia, C., Mack, W.J., et al. (1999) A Pooled Analysis of Case-Control Studies of Thyroid Cancer. IV. Benign Thyroid Diseases. Cancer Causes \& Control, 10, 583-595. 
https://doi.org/10.1023/A:1008907227706

[52] Rossing, M.A., Voigt, L.F., Wicklund, K.G., Williams, M. and Daling, J.R. (1998) Use of Exogenous Hormones and Risk of Papillary Thyroid Cancer (Washington, United States). Cancer Causes \& Control, 9, 341-349. https://doi.org/10.1023/A:1008833422577

[53] Sakoda, L.C. and Horn-Ross, P.L. (2002) Reproductive and Menstrual History and Papillary Thyroid Cancer Risk: The San Francisco Bay Area Thyroid Cancer Study. Cancer Epidemiology Biomarkers and Prevention, 11, 51-57.

[54] Mack, W.J., Preston-Martin, S., Dal Maso, L., Galanti, R., Xiang, M., Franceschi, S., et al. (2003) A Pooled Analysis of Case-Control Studies of Thyroid Cancer: Cigarette Smoking and Consumption of Alcohol, Coffee, and Tea. Cancer Causes \& Control, 14, 773-785. https://doi.org/10.1023/A:1026349702909

[55] Zidan, J., Karen, D., Stein, M., Rosenblatt, E., Basher, W. and Kuten, A. (2003) Pure versus Follicular Variant of Papillary Thyroid Carcinoma: Clinical Features, Prognostic Factors, Treatment, and Survival. Cancer, 97, 1181-1185.

https://doi.org/10.1002/cncr.11175

[56] Haugen, B.R., Alexander, E.K., Bible, K.C., Doherty, G.M., Mandel, S.J., Nikiforov, Y.E., et al. (2016) 2015 American Thyroid Association Management Guidelines for Adult Patients with Thyroid Nodules and Differentiated Thyroid Cancer: The American Thyroid Association Guidelines Task Force on Thyroid Nodules and Differentiated Thyroid Cancer. Thyroid, 26, 1-133. https://doi.org/10.1089/thy.2015.0020

[57] Lloyd, R.V., Buehler, D. and Khanafshar, E. (2011) Papillary Thyroid Carcinoma Variants. Head and Neck Pathology, 5, 51-56.

https://doi.org/10.1007/s12105-010-0236-9

[58] Thomas, R.M., Nancy, M.A.H., Perrier, D. and Grubbs, E.G. (2012) Well Differentiated Carcinoma of the Thyroid and Neoplasms of the Parathyroid Glands. 4th Edition, The M.D. Anderson Surgical Oncology Handbook: Fifth Edition. Vol. 1, Lippincott Williams and Wilkins, Philadelphia, 900.

[59] Johannessen, J.V. and Sobrinho-Simoes, M. (1980) The Origin and Significance of Thyroid Psammoma Bodies. Laboratory Investigation, 43, 287-296.

[60] Pacini, F., Elisei, R., Capezzone, M., Miccoli, P., Molinaro, E., Basolo, F., et al. (2001) Contralateral Papillary Thyroid Cancer Is Frequent at Completion Thyroidectomy with No Difference in Low- and High-Risk Patients. Thyroid, 11, 877-881. https://doi.org/10.1089/105072501316973145

[61] Rosai J, C.M. and De Lellis, R.A. (1992) Tumors of the Thyroid Gland. Atlas of Tumor Pathology. Armed Forces Institute of Pathology, Washington DC.

[62] Schindler, A.M., van Melle, G., Evequoz, B. and Scazziga, B. (1991) Prognostic Factors in Papillary Carcinoma of the Thyroid. Cancer, 68, 324-330. https://doi.org/10.1002/1097-0142(19910715)68:2\%3C324::AID-CNCR2820680220 \%3E3.0.CO;2-S

[63] Wallander, M., Layfield, L.J., Jarboe, E., Emerson, L., Liu, T., Thaker, H., et al. (2010) Follicular Variant of Papillary Carcinoma: Reproducibility of Histologic Diagnosis and Utility of HBME-1 Immunohistochemistry and BRAF Mutational Analysis as Diagnostic Adjuncts. Applied Immunohistochemistry \& Molecular Morphology, 18, 231-235. https://doi.org/10.1097/PAI.0b013e3181c61cdd

[64] Lloyd, R.V., Erickson, L.A., Casey, M.B., Lam, K.Y., Lohse, C.M., Asa, S.L., et al. (2004) Observer Variation in the Diagnosis of Follicular Variant of Papillary Thyroid Carcinoma. American Journal of Surgical Pathology, 28, 1336-1340. 
https://doi.org/10.1089/thy.2009.0073

[65] Rivera, M., Ricarte-Filho, J., Patel, S., Tuttle, M., Shaha, A., Shah, J.P., et al. (2010) Encapsulated Thyroid Tumors of Follicular Cell Origin with High Grade Features (High Mitotic Rate/Tumor Necrosis): A Clinicopathologic and Molecular Study. Human Pathology, 41, 172-180. https://doi.org/10.1016/j.humpath.2009.08.011

[66] Hawk, W.A. and Hazard, J.B. (1976) The Many Appearances of Papillary Carcinoma of the Thyroid. Cleveland Clinic Journal of Medicine, 43, 207-215.

[67] Johnson, T.L., Lloyd, R.V., Thompson, N.W., Beierwaltes, W.H. and Sisson, J.C. (1988) Prognostic Implications of the Tall Cell Variant of Papillary Thyroid Carcinoma. American Journal of Surgical Pathology, 12, 22-27.

https://doi.org/10.1097/00000478-198801000-00003

[68] Lappinga, P.J., Kip, N.S., Jin, L., Lloyd, R.V., Henry, M.R., Zhang, J. et al. (2010) $H M G A 2$ Gene Expression Analysis Performed on Cytologic Smears to Distinguish Benign from Malignant Thyroid Nodules. Cancer Cytopathology, 118, 287-297. https://doi.org/10.1002/cncy.20095

[69] Herrera, M.F., Hay, I.D., Wu, P.S.C., Goellner, J.R., Ryan, J.J., Ebersold, J.R., et al. (1992) Hurthle Cell (Oxyphilic) Papillary Thyroid Carcinoma: A Variant with More Aggressive Biologic Behavior. World Journal of Surgery, 16, 669-674. https://doi.org/10.1007/BF02067351

[70] Nassar, H. (2004) Carcinomas with Micropapillary Morphology: Clinical Significance and Current Concepts. Advances in Anatomic Pathology, 11, 297-303. https://doi.org/10.1097/01.pap.0000138142.26882.fe

[71] Evans, H.L. (1986) Columnar-Cell Carcinoma of the Thyroid. A Report of Two Cases of an Aggressive Variant of Thyroid Carcinoma. American Journal of Clinical Pathology, 85, 77-80. https://doi.org/10.1093/ajcp/85.1.77

[72] Li Volsi, A. (1995) Unusual Variants of Papillary Thyroid Carcinoma. Advances in Endocrinology and Metabolism, 6, 39-54.

[73] Nikiforov, Y. and Gnepp, D.R. (1994) Pediatric Thyroid Cancer after the Chernobyl Disaster. Pathomorphologic Study of 84 Cases (1991-1992) from the Republic of Belarus. Cancer, 74, 748-766.

https://doi.org/10.1002/1097-0142(19940715)74:2\%3C748::AID-CNCR2820740231 \%3E3.0.CO;2-H

[74] Koo, J.S., Hong, S. and Park, C.S. (2009) Diffuse Sclerosing Variant Is a Major Subtype of Papillary Thyroid Carcinoma in the Young. Thyroid, 19, 1225-1231. https://doi.org/10.1089/thy.2009.0073

[75] Albareda, M., Puig-Domingo, M., Wengrowicz, S., Soldevtla, J., Matias-Guiu, X., Caballero, A., et al. (1998) Clinical Forms of Presentation and Evolution of Diffuse Sclerosing Variant of Papillary Carcinoma and Insular Variant of Follicular Carcinoma of the Thyroid. Thyroid, 8, 385-391. https://doi.org/10.1089/thy.1998.8.385

[76] Sywak, M., Pasieka, J.L. and Ogilvie, T. (2004) A Review of Thyroid Cancer with Intermediate Differentiation. Journal of Surgical Oncology, 86, 44-54. https://doi.org/10.1002/jso.20044

[77] Yamashita, T., Hosoda, Y., Kameyama, K., Aiba, M., Ito, K. and Fujirnofo, Y. (1992) Peculiar Nuclear Clearing Composed of Microfilaments in Papillary Carcinoma of the Thyroid. Cancer, 70, 2923-2928. https://doi.org/10.1002/1097-0142(19921215)70:12\%3C2923::AID-CNCR282070123 2\%3E3.0.CO;2-G

[78] Yeoh, E.C., Lim, L.C., Ng, S.B., Tan, K.Y. and Rajasoorya, C. (2014) Cribriform morular Variant of Papillary Thyroid Carcinoma in a Patient with an Incidental 
Neck Lump: A Case Report and Review of the Literature. Endocrine Pathology, 25, 302-306. https://doi.org/10.1007/s12022-013-9274-7

[79] Lam, A.K., Lo, C.Y. and Lam, K.S. (2005) Papillary Carcinoma of Thyroid: A 30-yr Clinicopathological Review of the Histological Variants. Endocrine Pathology, 16, 323-330. https://doi.org/10.1385/EP:16:4:323

[80] Hirokawa, M., Shimizu, M., Terayama, K., Kanahara, T., Sonoo, H. and Manabe, T. (1998) Macrofollicular Variant of Papillary Thyroid Carcinoma. Report of a Case with Fine Needle Aspiration Biopsy Findings. Acta Cytologica, 42, 1441-1443. https://doi.org/10.1159/000332182

[81] Arrangoiz, R., Moran, R., Corona, L., Boy, J., Cordera, F., Caba, D., et al. (2020) Papillary Thyroid Carcinoma Hobnail Variant: A Report of Two Cases and Literature Review. American Journal of Otolaryngology and Head and Neck Surgery, 3, Article No. 1087.

[82] Asioli, S., Erickson, L.A., Sebo, T.J., Zhang, J., Jin, L., Thompson, G.B. and Lloyd, R.V. (2010) Papillary Thyroid Carcinoma with Prominent Hobnail Features: A New Aggressive Variant of Moderately Differentiated Papillary Carcinoma. A Clinicopathologic, Immunohistochemical, and Molecular Study of Eight Cases. American Journal of Surgical Pathology, 34, 44-52. https://doi.org/10.1097/PAS.0b013e3181c46677

[83] Lubitz, C.C., Economopoulos, K.P., Pawlak, A.C., Lynch, K., Dias-Santagata, D., Faquin, W.C., et al. (2014) Hobnail Variant of Papillary Thyroid Carcinoma: An Institutional Case Series and Molecular Profile. Thyroid, 24, 958-965. https://doi.org/10.1089/thy.2013.0573

[84] Lee, Y.S., Kim, Y., Jeon, S., Bae, J.S., Jung, S.L. and Jung, C.K. (2015) Cytologic, Clinicopathologic, and Molecular Features of Papillary Thyroid Carcinoma with Prominent Hobnail Features: 10 Case Reports and Systematic Literature Review. International Journal of Clinical and Experimental Pathology, 8, 7988-7997.

[85] Nandeesh, B.N., Ananthamurthy, A., Inchara, Y.K., Correa, M.M.A. and Garg, I. (2011) Papillary Thyroid Carcinoma with Nodular Fasciitis-Like Stroma: A Case Report. Ear, Nose \& Throat Journal, 90, E8-E10. https://doi.org/10.1177/014556131109001017

[86] Mizukami, Y., Kurumaya, H., Kitagawa, T., Minato, H., Nonomura, A., Michigishi, T., et al. (1995) Papillary Carcinoma of the Thyroid Gland with Fibromatosis-Like Stroma: A Case Report and Review of the Literature. Modern Pathology, 8, 366-370.

[87] Kim, H.J., Sohn, S.Y., Jang, H.W., Kim, S.W. and Chung, J.H. (2013) Multifocality, but Not Bilaterality, Is a Predictor of Disease Recurrence/Persistence of Papillary Thyroid Carcinoma. World Journal of Surgery, 37, 376-384. https://doi.org/10.1007/s00268-012-1835-2

[88] Carcangiu, M.L., Zampi, G., Pupi, A., Castagnoli, A. and Rosai, J. (1985) Papillary Carcinoma of the Thyroid. A Clinicopathologic Study of 241 Cases Treated at the University of Florence, Italy. Cancer, 55, 805-828.

https://doi.org/10.1002/1097-0142(19850215)55:4\%3C805::AID-CNCR2820550419 \%3E3.0.CO;2-Z

[89] Mazzaferri, E.L. and Jhiang, S.M. (1994) Long-Term Impact of Initial Surgical and Medical Therapy on Papillary and Follicular Thyroid Cancer. The American Journal of Medicine, 97, 418-428. https://doi.org/10.1016/0002-9343(94)90321-2

[90] Wang, L.Y. and Ganly, I. (2016) Nodal Metastases in Thyroid Cancer: Prognostic Implications and Management. Future Oncology, 12, 981-994.

https://doi.org/10.2217/fon.16.10 
[91] Wang, T.S., Dubner, S., Sznyter, L.A. and Heller, K.S. (2004) Incidence of Metastatic Well-Differentiated Thyroid Cancer in Cervical Lymph Nodes. Archives of Otolaryngology_Head and Neck Surgery, 130, 110-113. https://doi.org/10.1001/archotol.130.1.110

[92] Wada, N., Duh, Q.-Y., Sugino, K., Iwasaki, H., Kameyama, K., Mimura, T., et al. (2003) Lymph Node Metastasis from 259 Papillary Thyroid Microcarcinomas: Frequency, Pattern of Occurrence and Recurrence, and Optimal Strategy for Neck Dissection. Annals of Surgery, 237, 399-407.

https://doi.org/10.1097/01.SLA.0000055273.58908.19

[93] Pettersson, B., Adami, H.O., Wilander, E. and Coleman, M.P. (1991) Trends in Thyroid Cancer Incidence in Sweden, 1958-1981, by Histopathologic Type. International Journal of Cancer, 48, 28-33. https://doi.org/10.1002/ijc.2910480106

[94] Baloch, Z.W. and LiVolsi, V.A. (2018) Special Types of Thyroid Carcinoma. Histopathology, 72, 40-52. https://doi.org/10.1111/his.13348

[95] Tang, P.Y., Khor, L.Y. and Takano, A. (2017) Synchronous Papillary Thyroid Carcinoma and Medullary Thyroid Carcinoma-A Pitfall Waiting to Happen. The Malaysian Journal of Pathology, 39, 171-174.

[96] Lam, K.Y., Lo, C.-Y., Chan, K.-W. and Wan, K.-Y. (2000) Insular and Anaplastic Carcinoma of the Thyroid: A 45-Year Comparative Study at a Single Institution and a Review of the Significance of p53 and p21. Annals of Surgery, 231, 329-338. https://doi.org/10.1097/00000658-200003000-00005

[97] Pilotti, S., Collini, P., Mariani, L., Placucci, M., Bongarzone, I., Vigneri, P., et al. (1997) Insular Carcinoma: A Distinct de Novo Entity among Follicular Carcinomas of the Thyroid Gland. American Journal of Surgical Pathology, 21, 1466-1473. https://doi.org/10.1097/00000478-199712000-00009

[98] Burman, K.D., Ringel, M.D. and Wartofsky, L. (1996) Unusual Types of Thyroid Neoplasms. Endocrinology and Metabolism Clinics of North America, 25, 49-68. https://doi.org/10.1016/S0889-8529(05)70312-1

[99] Nikiforova, M.N. and Nikiforov, Y.E. (2008) Molecular Genetics of Thyroid Cancer: Implications for Diagnosis, Treatment and Prognosis. Expert Review of Molecular Diagnostics, 8, 83-95. https://doi.org/10.1586/14737159.8.1.83

[100] Jin, L., Seys, A.R., Zhang, S., Erickson-Johnson, M.R., Roth, C.W., Evers, B.R., et al. (2010) Diagnostic Utility of IMP3 Expression in Thyroid Neoplasms: A Quantitative RT-PCR Study. Diagnostic Molecular Pathology, 19, 63-69.

[101] Bilimoria, K.Y., Bentrem, D.J., Linn, J.G., Freel, A., Yeh, J.J., Stewart, A.K., et al. (2007) (Surgery) Utilization of Total Thyroidectomy for Papillary Thyroid Cancer in the United States. Surgery, 142, 906-913.E2. https://doi.org/10.1016/j.surg.2007.09.002

[102] Adam, M.A., Pura, J., Gu, L., Dinan, M.A., Tyler, D.S., Reed, S.D., et al. (2014) Extent of Surgery for Papillary Thyroid Cancer Is Not Associated with Survival: An Analysis of 61,775 Patients. Annals of Surgery, 260, 601-605. https://doi.org/10.1097/SLA.0000000000000925

[103] Mercante, G., Frasoldati, A., Pedroni, C., Formisano, D., Renna, L., Piana, S., et al. (2009) Prognostic Factors Affecting Neck Lymph Node Recurrence and Distant Metastasis in Papillary Microcarcinoma of the Thyroid: Results of a Study in 445 Patients. Thyroid, 19, 707-716. https://doi.org/10.1089/thy.2008.0270

[104] Perrino, M., Vannucchi, G., Vicentini, L., Cantoni, G., Dazzi, D., Colombo, C., et al. (2009) Outcome Predictors and Impact of Central Node Dissection and Radiometabolic Treatments in Papillary Thyroid Cancers $\leq 2 \mathrm{~cm}$. Endocrine-Related Cancer, 
16, 201-210. https://doi.org/10.1677/ERC-08-0119

[105] Lee, S.H., Lee, S.S., Jin, S.M., Kim, J.H. and Rho, Y.S. (2008) Predictive Factors for Central Compartment Lymph Node Metastasis in Thyroid Papillary Microcarcinoma. Laryngoscope, 118, 659-662. https://doi.org/10.1097/MLG.0b013e318161f9d1

[106] Arora, N., Turbendian, H.K., Scognamiglio, T., Wagner, P.L., Goldsmith, S.J., Zarnegar, R., et al. (2008) Extrathyroidal Extension Is Not All Equal: Implications of Macroscopic versus Microscopic Extent in Papillary Thyroid Carcinoma. Surgery, 144, 942-947. https://doi.org/10.1016/j.surg.2008.07.023

[107] Gemsenjager, E., Heitz, P.U. and Schweizer, I. (2001) Differentiated Thyroid Carcinoma. Follow-up of 264 Patients from One Institution for up to 25 Years. Swiss Medical Weekly, 131, 157-163. https://doi.org/10.4414/smw.2001.09679

[108] Brierley, J., Tsang, R., Panzarella, T. and Bana, N. (2005) Prognostic Factors and the Effect of Treatment with Radioactive Iodine and External Beam Radiation on Patients with Differentiated Thyroid Cancer Seen at a Single Institution over 40 Years. Clinical Endocrinology, 63, 418-427. https://doi.org/10.1111/j.1365-2265.2005.02358.x

[109] Chiang, F.Y., Lin, J.-C., Lee, K.-W., Wang, L.-F., Tsai, K.-B., Wu, C.-W., et al. (2006) Thyroid Tumors with Preoperative Recurrent Laryngeal Nerve Palsy: Clinicopathologic Features and Treatment Outcome. Surgery, 140, 413-417. https://doi.org/10.1016/j.surg.2006.02.006

[110] McCaffrey, J.C. (2000) Evaluation and Treatment of Aerodigestive Tract Invasion by Well-Differentiated Thyroid Carcinoma. Cancer Control, 7, 246-252. https://doi.org/10.1177\%2F107327480000700304

[111] Bilimoria, K.Y., Bentrem, D.J., Ko, C.Y., Stewart, A.K., Winchester, D.P., Talamonti, M.S., et al. (2007) Extent of Surgery Affects Survival for Papillary Thyroid Cancer. Annals of Surgery, 246, 375-384. https://doi.org/10.1097/SLA.0b013e31814697d9

[112] Alzahrani, A.S., Al Mandil, M., Chaudhary, M.A., Ahmed, M. and Eldin Mohammed, G. (2002) Frequency and Predictive Factors of Malignancy in Residual Thyroid Tissue and Cervical Lymph Nodes after Partial Thyroidectomy for Differentiated Thyroid Cancer. Surgery, 131, 443-449.

https://doi.org/10.1067/msy.2002.122377

[113] Mazzaferri, E.L. and Young, R.L. (1981) Papillary Thyroid Carcinoma: A 10 Year Follow-up Report of the Impact of Therapy in 576 Patients. American Journal of Medicine, 70, 511-518. https://doi.org/10.1016/0002-9343(81)90573-8

[114] Matsuzu, K., Sugino, K., Masudo, K., Nagahama, M., Kitagawa, W., Shibuya, H., et al. (2014) Thyroid Lobectomy for Papillary Thyroid Cancer: Long-Term Follow-up Study of 1,088 Cases. World Journal of Surgery, 38, 68-79.

https://doi.org/10.1007/s00268-013-2224-1

[115] Barney, B.M., Hitchcock, Y.J., Sharma, P., Shrieve, D.C. and Tward, J.D. (2011) Overall and Cause-Specific Survival for Patients Undergoing Lobectomy, Near-Total, or Total Thyroidectomy for Differentiated Thyroid Cancer. Head \& Neck, 33, 645-649. https://doi.org/10.1002/hed.21504

[116] Grant, C.S., Stulak, J.M., Thompson, G.B., Richards, M.L., Reading, C.C. and Hay, I.D. (2010) Risks and Adequacy of an Optimized Surgical Approach to the Primary Surgical Management of Papillary Thyroid Carcinoma Treated during 1999-2006. World Journal of Surgery, 34, 1239-1246. https://doi.org/10.1007/s00268-009-0307-9

[117] Ito, Y., Tomoda, C., Uruno, T., Takamura, Y., Miya, A., Kobayashi, K., et al. (2004) Preoperative Ultrasonographic Examination for Lymph Node Metastasis: Useful- 
ness When Designing Lymph Node Dissection for Papillary Microcarcinoma of the Thyroid. World Journal of Surgery, 28, 498-501. https://doi.org/10.1007/s00268-004-7192-Z

[118] Noguchi, S., Yamashita, H., Uchino, S. and Watanabe, S. (2008) Papillary Microcarcinoma. World Journal of Surgery, 32, 747-753.

https://doi.org/10.1007/s00268-007-9453-0

[119] Podnos, Y.D., Smith, D., Wagman, L.D. and Ellenhorn, J.D.I. (2005) The Implication of Lymph Node Metastasis on Survival in Patients with Well-Differentiated Thyroid Cancer. The American Surgeon, 71, 731-734. https://doi.org/10.1177\%2F000313480507100907

[120] Zaydfudim, V., Feurer, I.D., Griffin, M.R. and Phay, J.E. (2008) The Impact of Lymph Node Involvement on Survival in Patients with Papillary and Follicular Thyroid Carcinoma. Surgery, 144, 1070-1077. https://doi.org/10.1016/j.surg.2008.08.034

[121] Yu, X.M., Wan, Y., Sippel, R.S. and Chen, H. (2011) Should All Papillary Thyroid Microcarcinomas Be Aggressively Treated? An Analysis of 18,445 Cases. Annals of Surgery, 254, 653-660. https://doi.org/10.1097/SLA.0b013e318230036d

[122] Hegedus, L. (2004) Clinical Practice. The Thyroid Nodule. New England Journal of Medicine, 351, 1764-1771. https://doi.org/10.1056/NEJMcp031436

[123] Mandel, S.J. (2004) A 64-Year-Old Woman with a Thyroid Nodule. JAMA, 292, 2632-2642. https://doi.org/10.1001/jama.292.21.2632

[124] Tunbridge, W.M., Evered, D.C., Hall, R., Appleton, D., Brewis, M., Clark, F., et al. (1977) The Spectrum of Thyroid Disease in a Community: the Whickham Survey. Clinical Endocrinology, 7, 481-493. https://doi.org/10.1111/j.1365-2265.1977.tb01340.x

[125] Vander, J.B., Gaston, E.A. and Dawber, T.R. (1968) The Significance of Nontoxic Thyroid Nodules: Final Report of a 15-Year Study of the Incidence of Thyroid Malignancy. Annals of Internal Medicine, 69, 537-540. https://doi.org/10.7326/0003-4819-69-3-537

[126] Guth, S., Theune, U., Aberle, J., Galach, A. and Bamberger, C.M. (2009) Very High Prevalence of Thyroid Nodules Detected by High Frequency (13 MHz) Ultrasound Examination. European Journal of Clinical Investigation, 39, 699-706. https://doi.org/10.1111/j.1365-2362.2009.02162.x

[127] Gharib, H. and Papini, E. (2007) Thyroid Nodules: Clinical Importance, Assessment, and Treatment. Endocrinology and Metabolism Clinics of North America, 36, 707-735. https://doi.org/10.1016/j.ecl.2007.04.009

[128] Haymart, M.R., Repplinger, D.J., Leverson, G.E., Elson, D.F., Sippel, R.S., Jaume, J.C. and Chen, H. (2008) Higher Serum Thyroid Stimulating Hormone Level in Thyroid Nodule Patients Is Associated with Greater Risks of Differentiated Thyroid Cancer and Advanced Tumor Stage. Journal of Clinical Endocrinology \& Metabolism, 93, 809-814. https://doi.org/10.1210/jc.2007-2215

[129] Arrangoiz, R., Cordera, F., Caba, D., Moreno, E., de Leon, E.L. and Muñoz, M. (2018) Management Approach to Thyroid Nodules. International Journal of Otolaryngology and Head \& Neck Surgery, 7, 214-227. https://doi.org/10.4236/ijohns.2018.74023

[130] Suh, I., Vriens, M.R., Guerrero, M.A., Griffin, A., Shen, W.T., Duh, Q.-Y., et al. (2010) Serum Thyroglobulin Is a Poor Diagnostic Biomarker of Malignancy in Follicular and Hurthle-Cell Neoplasms of the Thyroid. The American Journal of Surgery, 200, 41-46. https://doi.org/10.1016/j.amjsurg.2009.08.030 
[131] Lee, E.K., Chung, K.W., Min, H.S., Kim, T.S., Kim, T.H., Ryu, J.S., et al. (2012) Preoperative Serum Thyroglobulin as a Useful Predictive Marker to Differentiate Follicular Thyroid Cancer from Benign Nodules in Indeterminate Nodules. Journal of Korean Medical Science, 27, 1014-1018.

https://doi.org/10.3346/jkms.2012.27.9.1014

[132] Elisei, R., Bottici, V., Luchetti, F., Di Coscio, G., Romei, C., Grasso, L., et al. (2004) Impact of Routine Measurement of Serum Calcitonin on the Diagnosis and Outcome of Medullary Thyroid Cancer: Experience in 10,864 Patients with Nodular Thyroid Disorders. Journal of Clinical Endocrinology \& Metabolism, 89, 163-168. https://doi.org/10.1210/jc.2003-030550

[133] Hahm, J.R., Lee, M.-S., Min, Y.-K., Lee, M.-K., Kim, K.-W., Nam, S.J., et al. (2001) Routine Measurement of Serum Calcitonin Is Useful for Early Detection of Medullary Thyroid Carcinoma in Patients with Nodular Thyroid Diseases. Thyroid, 11, 73-80. https://doi.org/10.1089/10507250150500694

[134] Costante, G., Meringolo, D., Durante, C., Bianchi, D., Nocera, M., Tumino, S., et al. (2007) Predictive Value of Serum Calcitonin Levels for Preoperative Diagnosis of Medullary Thyroid Carcinoma in a Cohort of 5817 Consecutive Patients with Thyroid Nodules. Journal of Clinical Endocrinology \& Metabolism, 92, 450-455. https://doi.org/10.1210/jc.2006-1590

[135] Niccoli, P., Wion-Barbot, N., Caron, P., Henry, J.-F., de Micco, C., Saint Andre, J.-P., et al. (1997) Interest of Routine Measurement of Serum Calcitonin: Study in a Large Series of Thyroidectomized Patients. The French Medullary Study Group. Journal of Clinical Endocrinology \& Metabolism, 82, 338-341. https://doi.org/10.1210/jcem.82.2.3737

[136] Smith-Bindman, R., Lebda, P., Feldstein, V.A., Sellami, D., Sellami, D., Goldstein, R.B., et al. (2013) Risk of Thyroid Cancer Based on Thyroid Ultrasound Imaging Characteristics: Results of a Population-Based Study. JAMA Internal Medicine, 173, 1788-1796. https://doi.org/10.1001/jamainternmed.2013.9245

[137] Brito, J.P., Gionfriddo, M.R., Al Nofal, A., Boehmer, K.R., Leppin, A.L., Reading, C., et al. (2014) The Accuracy of Thyroid Nodule Ultrasound to Predict Thyroid Cancer: Systematic Review and Meta-Analysis. Journal of Clinical Endocrinology \& Metabolism, 99, 1253-1263. https://doi.org/10.1210/jc.2013-2928

[138] Cibas, E.S. and Ali, S.Z. (2017) The 2017 Bethesda System for Reporting Thyroid Cytopathology. Thyroid, 27, 1341-1346. https://doi.org/10.1089/thy.2017.0500

[139] Horvath, E., Majlis, S., Rossi, R., Franco, C., Niedmann, J.P., Castro, A., et al. (2009) An Ultrasonogram Reporting System for Thyroid Nodules Stratifying Cancer Risk for Clinical Management. Journal of Clinical Endocrinology \& Metabolism, 94, 1748-1751. https://doi.org/10.1089/thy.2007.0014

[140] Ito, Y., Amino, N., Yokozawa, T., Ota, H., Ohshita, M., Murata, N., et al. (2007) Ultrasonographic Evaluation of Thyroid Nodules in 900 Patients: Comparison among Ultrasonographic, Cytological, and Histological Findings. Thyroid, 17, 1269-1276. https://doi.org/10.1089/thy.2007.0014

[141] Tae, H.J., Lim, D.J., Ki, H.B., Park, W.C., Lee, Y.S., Choi, J.E., et al. (2007) Diagnostic Value of Ultrasonography to Distinguish between Benign and Malignant Lesions in the Management of Thyroid Nodules. Thyroid, 17, 461-466.

https://doi.org/10.1089/thy.2006.0337

[142] Alexander, E.K., Heering, J.P., Benson, C.B., Frates, M.C., Doubilet, P.M., Cibas, E.S., et al. (2002) Assessment of Nondiagnostic Ultrasound-Guided Fine Needle Aspirations of Thyroid Nodules. Journal of Clinical Endocrinology \& Metabolism, 87, 4924-4927. https://doi.org/10.1210/jc.2002-020865 
[143] Danese, D., Sciacchitano, S., Farsetti, A., Andreoli, M. and Pontecorvi, A. (1998) Diagnostic Accuracy of Conventional versus Sonography-Guided Fine-Needle Aspiration Biopsy of Thyroid Nodules. Thyroid, 8, 15-21. https://doi.org/10.1089/thy.1998.8.15

[144] Baloch, Z.W. and LiVolsi, V.A. (2014) Follicular-Patterned Afflictions of the Thyroid Gland: Reappraisal of the Most Discussed Entity in Endocrine Pathology. Endocrine Pathology, 25, 12-20. https://doi.org/10.1007/s12022-013-9293-4

[145] Braga, M., Cavalcanti, T.C., Collaço, L.M. and Graf, H. (2001) Efficacy of Ultrasound-Guided Fine-Needle Aspiration Biopsy in the Diagnosis of Complex Thyroid Nodules. The Journal of Clinical Endocrinology \& Metabolism, 86, 4089-4091. https://doi.org/10.1210/jcem.86.9.7824

[146] Wu, H.H., Rose, C. and Elsheikh, T.M. (2012) The Bethesda System for Reporting Thyroid Cytopathology: An Experience of 1,382 Cases in a Community Practice Setting with the Implication for Risk of Neoplasm and Risk of Malignancy. Diagnostic Cytopathology, 40, 399-403. https://doi.org/10.1002/dc.21754

[147] Layfield, L.J., Abrams, J., Cochand-Priollet, B., Evans, D., Gharib, H., Greenspan, F., et al. (2008) Post-Thyroid FNA Testing and Treatment Options: A Synopsis of the National Cancer Institute Thyroid Fine Needle Aspiration State of the Science Conference. Diagnostic Cytopathology, 36, 442-448. https://doi.org/10.1002/dc.20832

[148] Singh, R.S. and Wang, H.H. (2011) Timing of Repeat Thyroid Fine-Needle Aspiration in the Management of Thyroid Nodules. Acta Cytologica, 55, 544-548.

https://doi.org/10.1159/000334214

[149] Lubitz, C.C., Nagarkatti, S.S., Faquin, W.C., Samir, A.E., Hassan, M.C., Barbesino, G., et al. (2012) Diagnostic Yield of Nondiagnostic Thyroid Nodules Is Not Altered by Timing of Repeat Biopsy. Thyroid, 22, 590-594.

https://doi.org/10.1089/thy.2011.0442

[150] Theoharis, C.G., Schofield, K.M., Hammers, L., Udelsman, R. and Chhieng, D.C. (2009) The Bethesda Thyroid Fine-Needle Aspiration Classification System: Year 1 at an Academic Institution. Thyroid, 19, 1215-1223. https://doi.org/10.1089/thy.2009.0155

[151] Luu, M.H., Fischer, A.H., Pisharodi, L. and Owens, C.L. (2011) Improved Preoperative Definitive Diagnosis of Papillary Thyroid Carcinoma in FNAs Prepared with Both ThinPrep and Conventional Smears Compared with FNAs Prepared with ThinPrep Alone. Cancer Cytopathology, 119, 68-73. https://doi.org/10.1002/cncy.20124

[152] Bongiovanni, M., Spitale, A., Faquin, W.C., Mazzucchelli, L. and Baloch, Z.W. (2012) The Bethesda System for Reporting Thyroid Cytopathology: A Meta-Analysis. Acta Cytologica, 56, 333-339. https://doi.org/10.1159/000339959

[153] Orlandi, A., Puscar, A., Capriata, E. and Fideleff, H. (2005) Repeated Fine-Needle Aspiration of the Thyroid in Benign Nodular Thyroid Disease: Critical Evaluation of Long-Term Follow-up. Thyroid, 15, 274-278. https://doi.org/10.1089/thy.2005.15.274

[154] Chehade, J.M., Silverberg, A.B., Kim, J., Case, C. and Mooradian, A.D. (2001) Role of Repeated Fine-Needle Aspiration of Thyroid Nodules with Benign Cytologic Features. Endocrine Practice, 7, 237-243. https://doi.org/10.4158/EP.7.4.237

[155] Oertel, Y.C., Miyahara-Felipe, L., Mendoza, M.G. and Yu, K. (2007) Value of Repeated Fine Needle Aspirations of the Thyroid: An Analysis of over Ten Thousand FNAs. Thyroid, 17, 1061-1066. https://doi.org/10.1089/thy.2007.0159

[156] Ito, Y., Miyauchi, A., Kihara, M., Higashiyama, T., Kobayashi, K. and Miya, A. 
(2014) Patient Age Is Significantly Related to the Progression of Papillary Microcarcinoma of the Thyroid under Observation. Thyroid, 24, 27-34.

https://doi.org/10.1089/thy.2013.0367

[157] Sugitani, I., Toda, K., Yamada, K., Yamamoto, N., Ikenaga, M. and Fujimoto, Y. (2010) Three Distinctly Different Kinds of Papillary Thyroid Microcarcinoma Should Be Recognized: Our Treatment Strategies and Outcomes. World Journal of Surgery, 34, 1222-1231. https://doi.org/10.1007/s00268-009-0359-x

[158] Tuttle, R.M. and Alzahrani, A.S. (2019) Risk Stratification in Differentiated Thyroid Cancer: From Detection to Final Follow-up. Journal of Clinical Endocrinology \& Metabolism, 104, 1087-4100. https://doi.org/10.1210/jc.2019-00177

[159] Ito, Y. and Miyauchi, A. (2019) Active Surveillance as First-Line Management of Papillary Microcarcinoma. Annual Review of Medicine, 70, 369-379.

https://doi.org/10.1146/annurev-med-051517-125510

[160] Brito, J.P., Ito, Y., Miyauchi, A. and Michael Tuttle, R. (2016) A Clinical Framework to Facilitate Risk Stratification When Considering an Active Surveillance Alternative to Immediate Biopsy and Surgery in Papillary Microcarcinoma. Thyroid, 26, 144-149. https://doi.org/10.1089/thy.2015.0178 